\title{
Dynamic Compressive Strength and Fragmentation in Sedimentary and Metamorphic Rocks
}

Auriol S. P. Rae ${ }^{1,2^{*}}$, Thomas Kenkmann ${ }^{1}$, Vivek Padmanabha ${ }^{1,3}$, Michael H. Poelchau ${ }^{1}$, Frank Schäfer ${ }^{1,3}$, Matthias A. Dörffler ${ }^{3}$, Louis Müller ${ }^{1}$

${ }^{1}$ Institute of Earth and Environmental Sciences - Geology, Albert-Ludwigs Universität Freiburg, Albertstrasse 23b, 79104 Freiburg, Germany.

${ }^{2}$ Department of Earth Sciences, University of Cambridge, Cambridge CB2 3EQ, UK

${ }^{3}$ Fraunhofer Institute for High-Speed Dynamics, Ernst-Mach-Institut (EMI), Ernst-Zermelostrasse 4, 79104 Freiburg, Germany.

*The lead author can be contacted by e-mail: auriol.rae@geologie.uni-freiburg.de or aspr2@cam.ac.uk,or Twitter:@ASprae.

This manuscript has been submitted for publication in TECTONOPHYSICS. This manuscript has not undergone peer review. Subsequent versions of this manuscript may have revised content. If accepted, the final version of this manuscript will be available via the 'Peer-reviewed Publication DOI' link on the right-hand side of this webpage. Please feel free to contact any of the authors; we welcome feedback. 


\title{
Dynamic Compressive Strength and Fragmentation in Sedimentary and Metamorphic Rocks
}

\author{
Auriol S. P. Rae ${ }^{1,2^{*}}$, Thomas Kenkmann¹, Vivek Padmanabha ${ }^{1,3}$, Michael H. Poelchau ${ }^{1}$, Frank \\ Schäfer ${ }^{1,3}$, Matthias A. Dörffler ${ }^{3}$, Louis Müller ${ }^{1}$ \\ ${ }^{1}$ Institute of Earth and Environmental Sciences - Geology, Albert-Ludwigs Universität Freiburg, \\ Albertstrasse 23b, 79104 Freiburg, Germany. \\ ${ }^{2}$ Department of Earth Sciences, University of Cambridge, Cambridge CB2 3EQ, UK \\ ${ }^{3}$ Fraunhofer Institute for High-Speed Dynamics, Ernst-Mach-Institut (EMI), Ernst-Zermelo- \\ strasse 4, 79104 Freiburg, Germany. \\ *Corresponding author: Auriol S. P. Rae (auriol.rae@geologie.uni-freiburg.de)
}

\begin{abstract}
Brittle deformation at high strain rates results in intense fragmentation and rock pulverisation. For rocks, the critical strain rate at which this behaviour occurs is $\sim 10^{2} \mathrm{~s}^{-1}$. The mechanical properties of rocks at these strain rates can also be very different from their quasi-static properties. Deformation of rocks at these strain rates is uncommon in nature but can occur during fault rupture, landslide events, and meteorite impacts. In this study, we present results of high strain rate mechanical tests to determine the characteristic strain rate for rate-dependent brittle failure, and the fragment size and shape distributions that result from failure at these conditions. We investigated sandstone, quartzite, limestone, and marble and considered whether the fragment characteristics can be used as diagnostic indicators of loading conditions during brittle failure. We find that the characteristic strain rates, where the dynamic strength is twice the quasi-static strength, range between $\sim 150$ and $300 \mathrm{~s}^{-1}$ for rate-dependent brittle failure in the investigated lithologies. Furthermore, we use our results to demonstrate an empirical inverse power-law relationship between fragment size and strain rate for dynamic failure under uniaxial compression. On the other hand, we show that fragment shape is independent of strain rate under dynamic uniaxial loading.
\end{abstract}




\section{Keywords}

Dynamic Failure; Strength; Strain Rate; Fragmentation; Pulverised Fault Rocks; Brittle Deformation

\section{Highlights:}

- Brittle failure in sedimentary and metamorphic rocks is rate-dependent at characteristic rates of $\sim 150-300 \mathrm{~s}^{-1}$.

- An empirical relationship between strain rate and fragment size is derived for nonporous and porous rocks.

- Fragment size can be used as a diagnostic indicator of transient loading conditions during dynamic compressive failure.

- Fragment shape is independent of strain rate and cannot be used as a diagnostic indicator of transient loading conditions during dynamic compressive failure. 


\section{Introduction}

Fragmentation of rocks occurs during a variety of geological processes, including seismogenic fault rupture (Aben et al., 2017), gravitational mass movements (De Blasio and Crosta, 2014), and meteorite impacts (Kenkmann et al., 2014). In all these events, brittle failure may occur under dynamic, high strain rate conditions. At these conditions, the mechanical properties of rocks (Zhang and Zhao, 2014), the behaviour of individual fractures (Fineberg et al., 1991; Ravi-Chandar and Knauss, 1984a; Sharon and Fineberg, 1999; Zhang et al., 1999), and the interaction between growing fractures (Ramesh et al., 2015) can be strongly rate-dependent and deviate from quasistatic brittle failure.

The results of mechanical experiments demonstrate that rocks behave with a strength that is near constant at low strain rates before increasing markedly beyond a threshold strain rate of $\sim 10^{0}$ - $10^{3} \mathrm{~s}^{-1}$ (Aben et al., 2017; Ramesh et al., 2015; Zhang and Zhao, 2014, and refs. therein). A number of analytical and micromechanical models have been developed that demonstrate this increase in strength (Bhat et al., 2012; Hild et al., 2003; Paliwal and Ramesh, 2008). In a study that explored one of these micromechanical models (Paliwal and Ramesh, 2008), Kimberley et al. (2013) demonstrated that the behaviour of rocks from quasi-static to high strain rates can be described by a universal scaling relationship:

$$
\frac{\sigma_{c}}{\sigma_{0}}=1+\frac{\dot{\varepsilon}^{\frac{2}{3}}}{\dot{\varepsilon}_{0}},(1)
$$

where $\sigma_{c}$ and $\dot{\varepsilon}$ are the compressive strength and strain rate, respectively, and the material parameters, $\sigma_{0}$ and $\dot{\varepsilon}_{0}$, are the characteristic strength and characteristic strain rate, respectively. The characteristic strength is equivalent to the quasi-static uniaxial compressive strength and the characteristic strain rate corresponds to the strain rate at which strength is double the value of the quasi-static strength.

The dependence of rock strength on strain rate is fundamentally linked to the nucleation and growth of fractures. Fractures propagate at a finite velocity: during failure at low rates, the weakest available flaw in a material can initiate a single fracture that can grow fast enough to accommodate the applied loading; at high rates, that single flaw cannot develop a single fracture before other increasingly strong flaws are activated (Aben et al., 2017; Ramesh et al., 2015). Furthermore, it has been demonstrated that the behaviour of individual fractures may change as a result of high- 
rate loading; increasing fracture toughness and producing hierarchical fracture branches (RaviChandar and Knauss, 1984a; Sharon and Fineberg, 1999; Zhang et al., 1999). The consequence of these processes is that rock failure at high strain rates leads to intense fracturing and fragmentation.

Upper crustal fault zones generally consist of a fault core and a surrounding damage zone. The fault core contains highly comminuted material that accommodates most of the cumulative shear strain while the damage zone consists of fragmented and brecciated rock with little or no shear displacement (Faulkner et al., 2003). Brittle deformation in the damage zone is generated by coseismic transient loading conditions; either by rapid reduction of normal stress (Brune et al., 1993), local strain near fracture tips (Reches and Dewers, 2005), and/or the propagation of shock waves during supershear rupturing (Doan and Gary, 2009). Coseismic fracturing and fragmentation, the extent and magnitude of which is controlled by the loading rate, may be an important component of the energy budget of rupture events (Barber and Griffith, 2017; Ghaffari et al., 2019; Rockwell et al., 2009; Wilson et al., 2005). The most extreme deformation caused by coseismic dynamic fracturing is thought to be expressed in so-called pulverised rocks, which have extremely high fracture densities and low shear strain. These rocks can be found tens to hundreds of meters from their fault core (Dor et al., 2006a; Fondriest et al., 2015; Mitchell et al., 2011; Rempe et al., 2013).

The close link between the variation of strength with strain rate and fragmentation behaviour has been demonstrated with a variety of dynamic uniaxial compression experiments (Barber and Griffith, 2017; Doan and Billi, 2011; Doan and Gary, 2009; Ghaffari et al., 2019; Yao et al., 2020; Yuan et al., 2011). Furthermore, fragmentation laws have been proposed that describe the variation of fragment size in an expanding shell as a function of the applied strain rate (Glenn and Chudnovsky, 1986; Grady, 1982; Levy and Molinari, 2010; Zhou et al., 2006a, 2006b), all of these models consistently predict that, at high strain rates, fragment size has an inverse power-law relationship with strain rate with an exponent of $2 / 3$. This exponent arises as a consequence of the equilibrium conversion of kinetic energy released in fragmentation $\left(U_{k} \propto s^{5} \dot{\varepsilon}^{2}\right.$, where $s$ is the fragment size) to fracture surface energy $\left(U_{s} \propto s^{2}\right)$ (Grady, 1982). Direct comparisons between fragmentation models and the products of compressive failure are problematic because the fragmentation of an expanding shell is a tensile process. However, in general, experimental studies have shown that the fragmentation models overestimate average fragment sizes and/or do not 
follow a power law with the expected exponent (Ghaffari et al., 2019; Hogan et al., 2013, 2012; Lankford and Blanchard, 1991; Rae et al., 2020; Wang and Ramesh, 2004). Nevertheless, the combination of experimental and/or theoretical fragmentation models with field observations of naturally fragmented rock masses provides an important opportunity to determine transient loading conditions during coseismic deformation or other high-strain rate geoprocesses (Rowe and Griffith, 2015).

In this study, we aim to investigate the fragmentation behaviour of rocks under dynamic loading, characterising how fragment size and shape varies as functions of strain rate, therefore providing potential diagnostic indicators of transient loading conditions in naturally deformed rocks. To achieve this, we conduct quasi-static and dynamic uniaxial loading experiments on rock materials, determining dynamic rock mechanical properties and performing post-mortem analysis of the generated rock fragments. For this study, we decided to limit our investigation to sedimentary and metamorphic rocks: sandstone, quartzite, limestone, and marble. These rock types were chosen because, first, pulverisation has been widely reported in association with faults hosted in sandstones (Dor et al., 2006a, 2006b; Key and Schultz, 2011; Peppard et al., 2018) and carbonates (Agosta and Aydin, 2006; Fondriest et al., 2015; Sagy and Korngreen, 2012;

Schröckenfuchs et al., 2015), and second, it allowed us to investigate the effect of porosity on fragmentation and dynamic material properties in lithologies with similar mineralogies.

\section{Methods}

\subsection{Material Description}

The sandstone used in this study was quarried by TRACO Deutsche Travertin Werke $\mathrm{GmbH}$ at Seeberg near Gotha, Germany, hereafter termed 'Seeberger Sandstone'. Quartzite was acquired from Taunus-Quartzit-Werke GmbH \& Co., Wehrheim, Germany, hereafter termed 'Taunus Quartzite'. Limestone was acquired from Savonnières-en-Perthois, Lorraine, France, hereafter termed "Savonnières Limestone". Marble was acquired from the Amso International Company, Tuscany, Italy, hereafter termed 'Carrara Marble'.

The Seeberger Sandstone is composed of $89 \%$ quartz, 10\% phyllosilicates (mostly clay minerals and subordinate micas), and minor accessory minerals (Ebert et al., 2014). Grain sizes 
range between $\sim 50-150 \mu \mathrm{m}$. Macroscopically, weakly developed bedding and Liesegang banding can be observed, but do not cause significant mechanical anisotropy. The bulk density and porosity of the Seeberger Sandstone was determined by He-pycnometry to be $2130 \pm 21 \mathrm{~kg} \mathrm{~m}^{-3}$ and $20.0 \pm$ $0.8 \%$ respectively. The Taunus Quartzite is composed of $91 \%$ quartz, $\sim 8 \%$ phyllosilicates, and minor accessory minerals (Ebert et al., 2014). Grain sizes range from $\sim 100-400 \mu \mathrm{m}$. The quartzite contains minor joints with an approximate spacing of $10 \mathrm{~cm}$, the joints are commonly mineralized with chlorite. The bulk density and porosity of the Taunus Quartzite was determined by Hepycnometry to be $2645 \pm 6 \mathrm{~kg} \mathrm{~m}^{-3}$ and $0.6 \pm 0.1 \%$ respectively. The Savonnières Limestone is an oolitic grainstone with partial sparitic cement. Vacuolar ooids are common and the rock contains occasional shell fragments. Mineralogically, the rock is composed of close to $100 \%$ calcite. The ooids typically range in size from 400 to $750 \mu \mathrm{m}$. The bulk density and porosity of the Savonnières Limestone was determined by He-pycnometry to be $1881 \pm 31 \mathrm{~kg} \mathrm{~m}^{-3}$ and $31.4 \pm 1.1 \%$ respectively. The Carrara Marble is composed of $98 \%$ calcite, and minor quantities of quartz, mica, dolomite, epidote, and pyrite (Pieri et al., 2001). Grain sizes range from $200-400 \mu \mathrm{m}$. Calcite grains are commonly twinned. In hand specimen, the marble is massive and homogeneous. The bulk density and porosity of the Carrara Marble was determined by He-pycnometry to be 2711 $\pm 6 \mathrm{~kg} \mathrm{~m}^{-3}$ and $0.3 \pm 0.0 \%$ respectively.

The samples used for rock deformation experiments were cored from blocks of each lithology. Typical samples were $\sim 41 \mathrm{~mm}$ in diameter, however cores of the Taunus Quartzite were $\sim 35 \mathrm{~mm}$ in diameter for a number of reasons: firstly, the Taunus Quartzite is very strong, narrower diameter cores made it easier to achieve failure with the SHPB. Secondly, the joints within the Taunus Quartzite made drilling challenging, reducing core diameter made it easier to produce appropriate samples. Additionally, cores of the Savonnières Limestone were $\sim 54 \mathrm{~mm}$ in diameter for quasi-static uniaxial compressive strength (UCS) testing due to the material's extreme weakness; larger diameter samples ensured that a larger force could be applied to the samples and that a greater amount of data could be recorded in the elastic regime. The lengths of the samples were maintained such that samples had 1:1 aspect ratios for SHPB experiments (Zhang and Zhao, 2014; Zhou et al., 2011) and 2:1 aspect ratios for quasi-static UCS testing (Hawkes and Mellor, 1970; Hawkins, 1998). In total, 90 experiments were conducted in this study. 27 and 20 experiments were carried out on the Seeberger Sandstone and Taunus Quartzite, respectively. 18 
and 25 experiments were carried out on the Savonnières Limestone and Carrara Marble, respectively. 

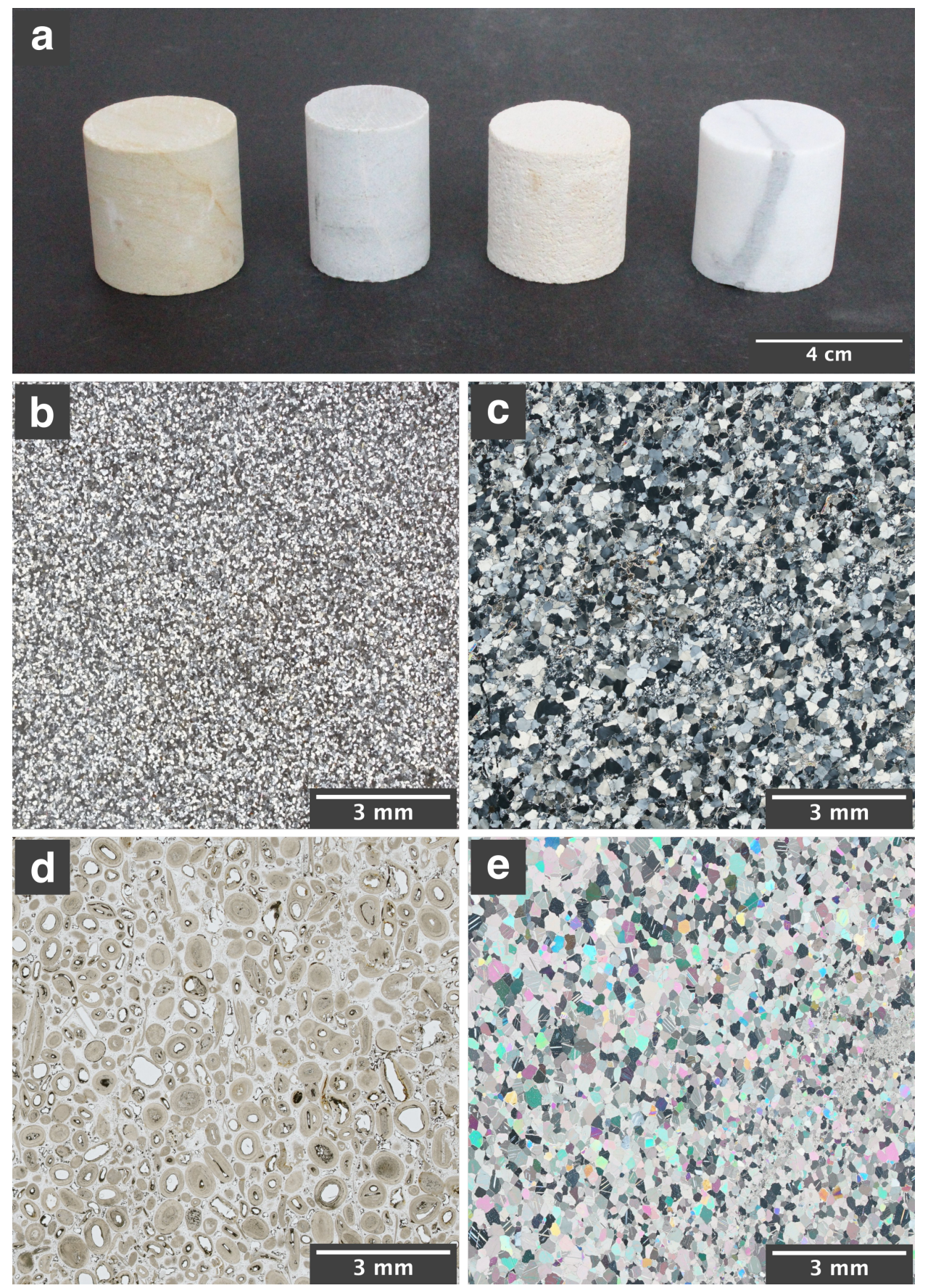

Figure 1. Sample lithologies. a) Hand specimens of (from left to right) Seeberger Sandstone, Taunus Quartzite, Savonnières Limestone, and Carrara Marble. b-e) Thin section images of the four lithologies: b) Seeberger Sandstone under cross-polarised light, c) Taunus Quartzite under cross-polarised light, d) Savonnières Limestone under plane-polarised light, and e) Carrara Marble under cross-polarised light. 


\subsection{Experimental Rock Deformation}

\subsubsection{Quasi-static}

Uniaxial compression experiments under quasi-static conditions were performed with a servo-controlled Form+Test Alpha 2-3000 S hydraulic press in the Department of Geology at the University of Freiburg. Longitudinal and transverse strains in the samples were measured using displacement gauges. Experiments were run under constant loading-rate conditions, which, within the elastic loading regime leads to constant strain rates. Experiments were run at strain rates between $5.3 \times 10^{-6}$ and $3.4 \times 10^{-5} \mathrm{~s}^{-1}$. Between 3 and 8 quasi-static experiments were carried out for each lithology.

\subsubsection{Dynamic}

Uniaxial compression experiments under dynamic conditions were performed with a split Hopkinson pressure bar (SHPB) in the Department of Geology at the University of Freiburg. SHPBs are comprised of three bars: striker, incident, and transmission. The sample is positioned between and in contact with the incident and transmission bars. The striker bar is accelerated towards the front-end of the incident bar, generating a stress wave that propagates towards the sample and transmission bar. The amplitude of the stress wave is low enough not to induce permanent deformation in the bars but can be high enough to induce failure in the sample material. Strain gauges are attached to the incident and transmission bars such that the stress and strain history of the sample can be determined (see Supplementary Material). In this study, strain rates in failed specimens during SHPB experiments were between $35.5 \pm 7.4$ and $345.5 \pm 83.2 \mathrm{~s}^{-1}$. A detailed description of the methodology and processing of SHPB data, including strain rate and strength determination, is provided in the Supplementary Material and provided in a GitHub Repository. General descriptions of the methodology of SHPBs can be found by Aben et al. (2017); Chen and Song (2010); Xia and Yao (2015); Zhang and Zhao (2014); Zhou et al. (2011); and Zwiessler et al. (2017). Samples were recovered from the SHPB by collection in a secure box lined with a polyethylene bag.

\subsection{Fragment Analysis}




\subsubsection{Size}

On average, we were able to recover $88.2 \%$ of the mass of each sample from the SHPB experiments, recovery was generally poorer in the sandstone and limestone, with average recoveries of $83.4 \%$ and $84.4 \%$ respectively, while $95.5 \%$ and $88.6 \%$ recoveries were achieved with the quartzite and marble respectively (see GitHub repository for further details). Fragment size distributions were obtained by sieving the fragmented rock masses resulting from the experiments. Each sample of the same lithology were passed through identical sieve stacks, although sieve stacks were varied between lithology. Each sieve stack had at least 7 sieves ranging from $16 \mathrm{~mm}$ to $0.125 \mathrm{~mm}$ square apertures. Sieving was carried out dry and shaking was carried out by hand for a duration of one minute per sample.

A consequence of using sieving to determine fragment size distributions is that it results in mass-size distributions, as opposed to number-size distributions. A variety of statistical distributions can be used to fit fragment size distributions from failure events (see Grady, 2010). Here, we have chosen to use cumulative Weibull distributions:

$$
\frac{M(s)}{M_{T}}=1-\exp \left[-\left(\frac{s}{\lambda}\right)^{k}\right]
$$

where $M(s)$ is the cumulative mass of fragments that have a size less than $s ; M_{T}$ is the total sample mass; and $\lambda$ and $\mathrm{k}$ are the scale and shape parameters of the distribution respectively. There is no theoretical basis for our usage of the Weibull distribution which we chose only for its simplicity, general usage (Grady, 2009), and approximate match to the shape of our data. Non-linear least squares fitting was used to determine the Weibull distributions. Other distributions could have been used to fit our fragment size data, e.g., Rayleigh (Levy and Molinari, 2010), log-normal (Wang and Ramesh, 2004), or generalized extreme value (Hogan et al., 2012). The median of a Weibull distribution, $\bar{s}$, can be calculated as:

$$
\bar{s}=\lambda \ln (2)^{1 / k}
$$

In the case of the quartzite, limestone, and marble, no more than $26 \%$ and on average $2 \%$, $8 \%$, and $16 \%$ respectively of the total mass of the samples passed the finest sieve. Thus, for these lithologies, the median fragment size is an interpolated value within the distribution. However, the sandstone produced substantially finer fragments such that on average $42 \%$ of the total mass of the samples passed the finest sieve. In 5 sandstone samples, the mass percentage passing through 
the finest sieve exceeded $50 \%$, and therefore the calculated median fragment size is extrapolated below the size of the finest sieve size. We were unable to extend these distributions to finer fragment sizes due to unreliability of dry sieving through finer sieves. Additionally, we attempted to use laser diffraction granulometry (Malvern MasterSizer 3000) on the fine fragments but were unable to achieve consistent overlap between sieving and laser diffraction analyses and between different runs of the laser diffraction granulometer on the same sample to extend the fragment size distributions to smaller fragment size. Our problems of integrating fragment size distributions across different methodologies are similar to those reported by Rockwell et al. (2009) on pulverized rocks from the San Andreas and Garlock faults in southern California.

\subsubsection{Shape}

The shapes of fragments generated by the experiments were determined by image analysis. We focussed on two size fractions: fragments larger than $2 \mathrm{~mm}$, and fragments from 0.5 to $2 \mathrm{~mm}$ in size. These size fractions had to be imaged separately and followed different image processing procedures for a variety of practical reasons (for details, see Supplementary Material). Images were processed using the Fiji software package (Schindelin et al., 2012; see Supplementary Material for details) and fragment shape parameters were determined for each fragment. Here, we have considered two shape factors, circularity, C, and axial ratio, AR (Heilbronner and Barrett, 2014):

$$
\begin{aligned}
& C=4 \pi \frac{A}{P^{2}},(4) \\
& A R=\frac{w}{l},(5)
\end{aligned}
$$

where $\mathrm{A}$ is the area of the fragment, $\mathrm{P}$ is the perimeter of the fragment, $\mathrm{w}$ is the minor axis length of the best-fitting ellipse, and 1 is the major axis length of the best-fitting ellipse. $\mathrm{C}$ has a value of 1 for a perfect circle and approaches 0 as the shape's perimeter increases relative to its area. AR has a value of 1 for a perfectly equant shape, i.e. any regular polyhedra, and approaches 0 as the shape becomes increasingly elongate. 


\section{Results}

\subsection{Mechanical Data}

In general, results of mechanical testing demonstrate dynamic strength increase under uniaxial compression at large strain rates. The quasi-static and dynamic uniaxial compressive strength (UCS) values can be individually fitted to the scaling relationship of Kimberley et al. (2013) (Equation 1) by non-linear least squares fitting (Figure 2). The characteristic stress (i.e. the UCS) of the sandstone, quartzite, limestone, and marble were determined to be $55.8 \pm 3.6$, $243.3 \pm 15.6,18.6 \pm 1.5$, and 97.8 $\pm 6.7 \mathrm{MPa}$ respectively (Table 1). The characteristic strain rates of the sandstone, quartzite, limestone, and marble are $322 \pm 92,280 \pm 92,241 \pm 78$, and $144 \pm 33$ $\mathrm{s}^{-1}$ respectively (Table $\left.\mathbf{1}\right)$. 


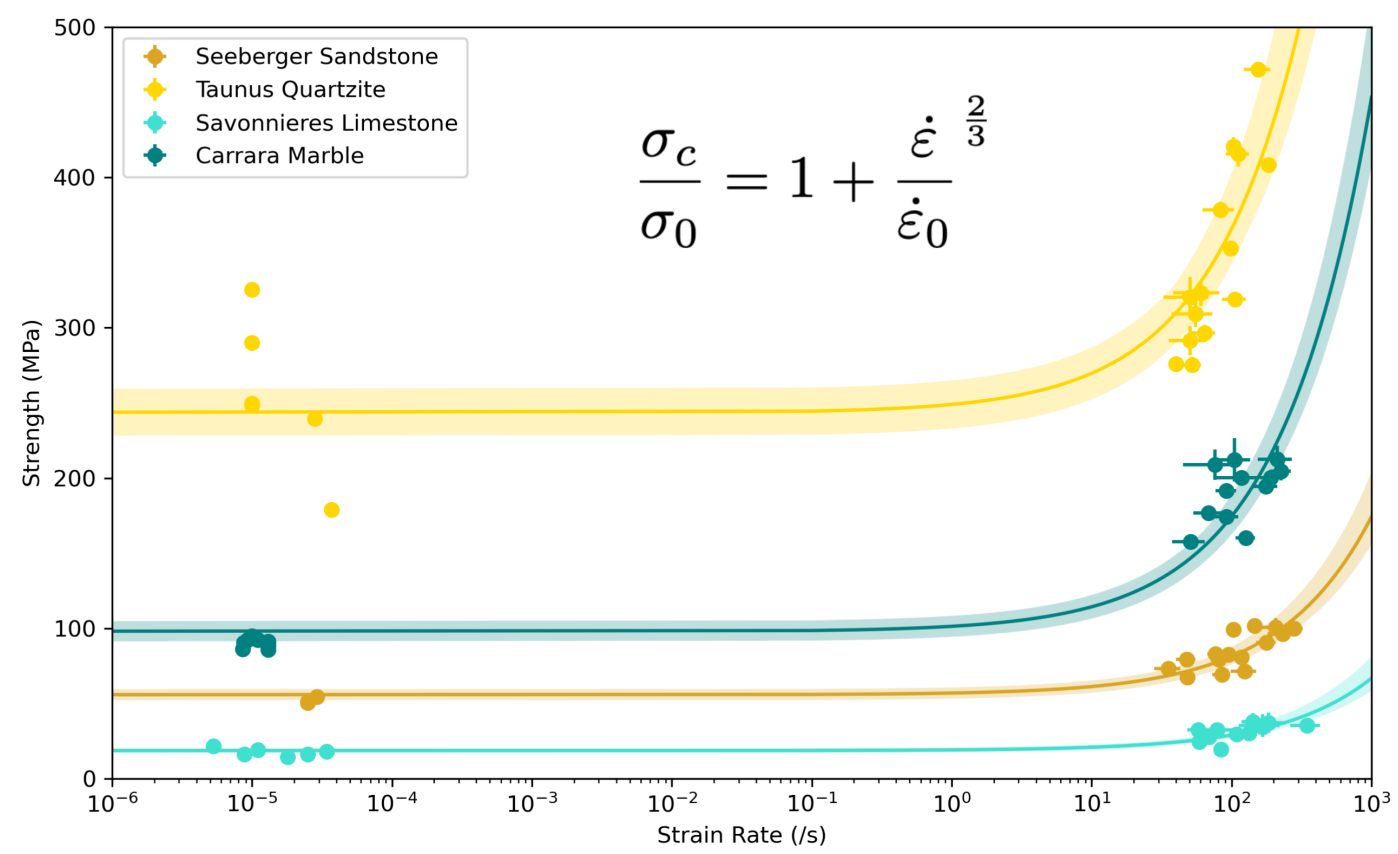

Figure 2. Compressive strengths from quasi-static and dynamic testing at various strain rates. Each lithology follows the universal scaling relationship of Kimberley et al. (2013), each fitted curve is shown with $1 \sigma$ error envelopes. Data presented with a linear X-axis are shown in Supplementary Figure 2. The material parameters, $\sigma_{0}$ and $\dot{\varepsilon}_{\mathbf{0}}$, and their uncertainties are reported in Table $\mathbf{1}$. 
Table 1. Measured material properties of the Seeberger Sandstone, Taunus Quartzite, Savonnières Limestone, and Carrara Marble.

\begin{tabular}{|c|c|c|c|c|}
\hline & $\begin{array}{l}\text { Seeberger } \\
\text { Sandstone }\end{array}$ & $\begin{array}{c}\text { Taunus } \\
\text { Quartzite }\end{array}$ & $\begin{array}{c}\text { Savonnières } \\
\text { Limestone }\end{array}$ & $\begin{array}{l}\text { Carrara } \\
\text { Marble }\end{array}$ \\
\hline$\rho\left(\mathrm{kg} \mathrm{m}^{-3}\right)$ & $2130 \pm 21$ & $2645 \pm 6$ & $1881 \pm 31$ & $2711 \pm 6$ \\
\hline$\varphi(\%)$ & $20.0 \pm 0.8$ & $0.6 \pm 0.1$ & $31.4 \pm 1.1$ & $0.3 \pm 0.0$ \\
\hline$E(G P a)$ & $13.8 \pm 0.6$ & $38.1 \pm 5.9$ & $11.5 \pm 2.1$ & $44.8 \pm 3.0$ \\
\hline$v$ & $0.373 \pm 0.050$ & $0.099 \pm 0.022$ & $0.197 \pm 0.044$ & $0.245 \pm 0.026$ \\
\hline$\sigma_{0}(M P a)$ & $55.8 \pm 3.6$ & $243.3 \pm 15.6$ & $18.6 \pm 1.5$ & $97.8 \pm 6.7$ \\
\hline$\dot{\varepsilon}_{0}\left(s^{-1}\right)$ & $322 \pm 92$ & $280 \pm 92$ & $241 \pm 78$ & $144 \pm 33$ \\
\hline$N$ & $2.90 \pm 0.63$ & $1.45 \pm 0.36$ & $0.65 \pm 0.23$ & $1.45 \pm 0.41$ \\
\hline$V_{p}\left(m s^{-1}\right)^{*}$ & $3413 \pm 480$ & $3837 \pm 298$ & $2602 \pm 273$ & $4433 \pm 181$ \\
\hline \multirow{2}{*}{\multicolumn{5}{|c|}{$\begin{array}{l}\mathrm{E}=\text { Quasi-static Elastic Modulus, } \nu=\text { Quasi-static Poisson's Ratio, } \rho=\text { Bulk Density, } \varphi=\text { Porosity, } \\
\sigma_{0}=\text { Characteristic Stress (i.e. Quasi-static Uniaxial Compressive Strength), } \dot{\varepsilon}_{0}=\text { Characteristic } \\
\text { Strain Rate, } N=\text { Power-law exponent of fragment size vs. strain rate, } V_{p}=\text { P-wave velocity. * }\end{array}$}} \\
\hline & & & & \\
\hline \multicolumn{5}{|c|}{ Calculated from elastic properties, $v_{p}=\sqrt{\frac{E(1-v)}{(1+v)(1-2 v) \rho}}$} \\
\hline
\end{tabular}




\subsection{Fragment Size Distributions}

Fragment size distributions and their fitted Weibull distributions for the sandstone, quartzite, limestone, and marble are shown on Figure 3a-d. All distributions are characterized by increasing fractions of fine-grained material at larger strain rates. Weibull distributions produce very good fits to the fragment size distributions of the Savonnières Limestone, while providing good fits to the Seeberger Sandstone and Taunus Quartzite distributions. The Carrara Marble distributions are, in general, less well fitted by Weibull distributions, however, the median values of those fitted distributions tend to closely match the linearly interpolated $50^{\text {th }}$ percentile value of the distribution and therefore, we continued to use the Weibull distribution fits to determine the average grain size of each distribution. Average fragment sizes for each lithology decrease with increasing strain rate (Figure 4). Each lithology follows an inverse power law where the exponents for the sandstone, quartzite, limestone, and marble are $2.90 \pm 0.63,1.45 \pm 0.36,0.65 \pm 0.23$, and $1.45 \pm 0.41$, respectively. 

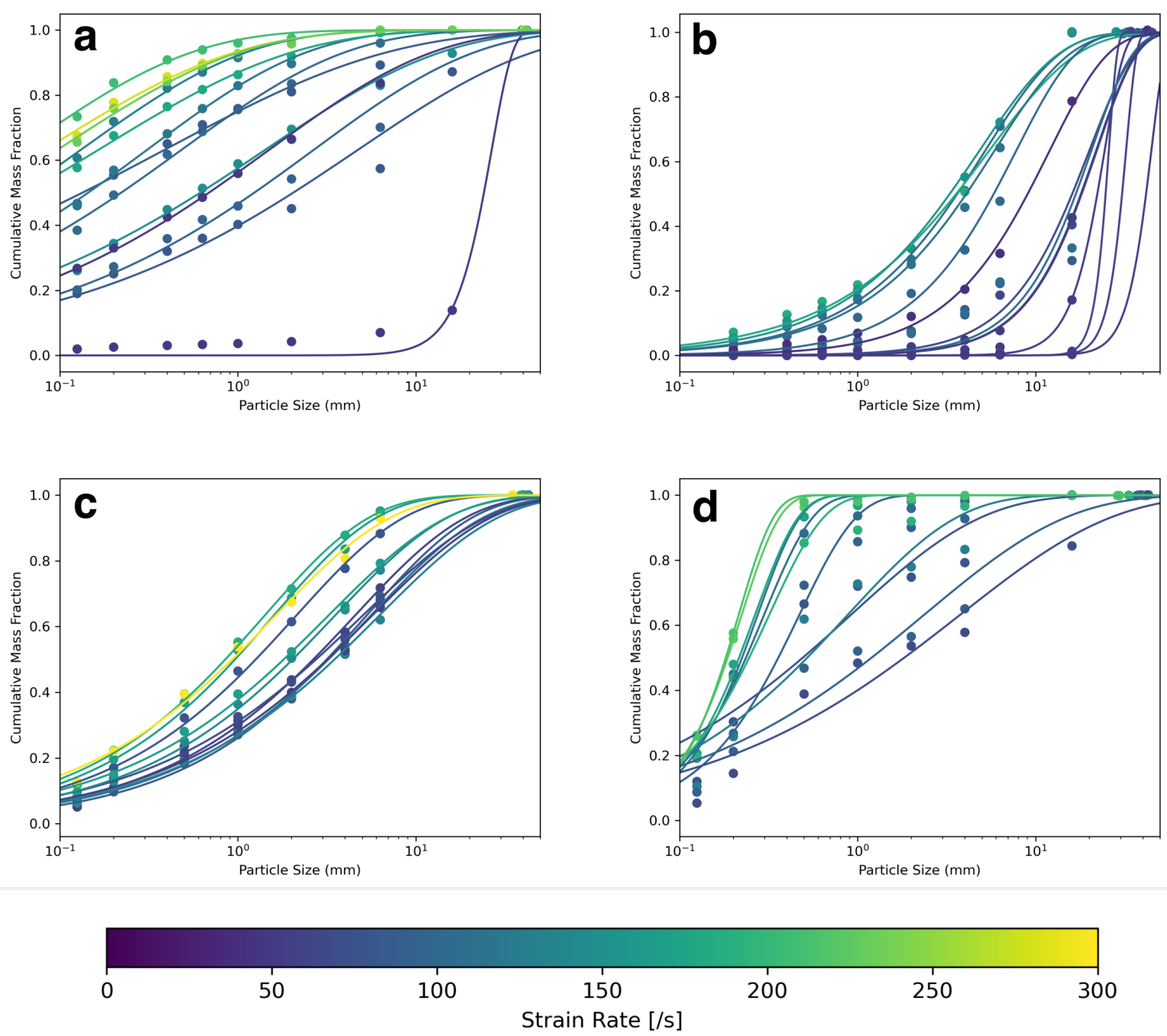

Figure 3. Cumulative mass fragment size distributions colored by strain rate for a) Seeberger Sandstone, b) Taunus Quartzite, c) Savonnières Limestone, and d) Carrara Marble. 


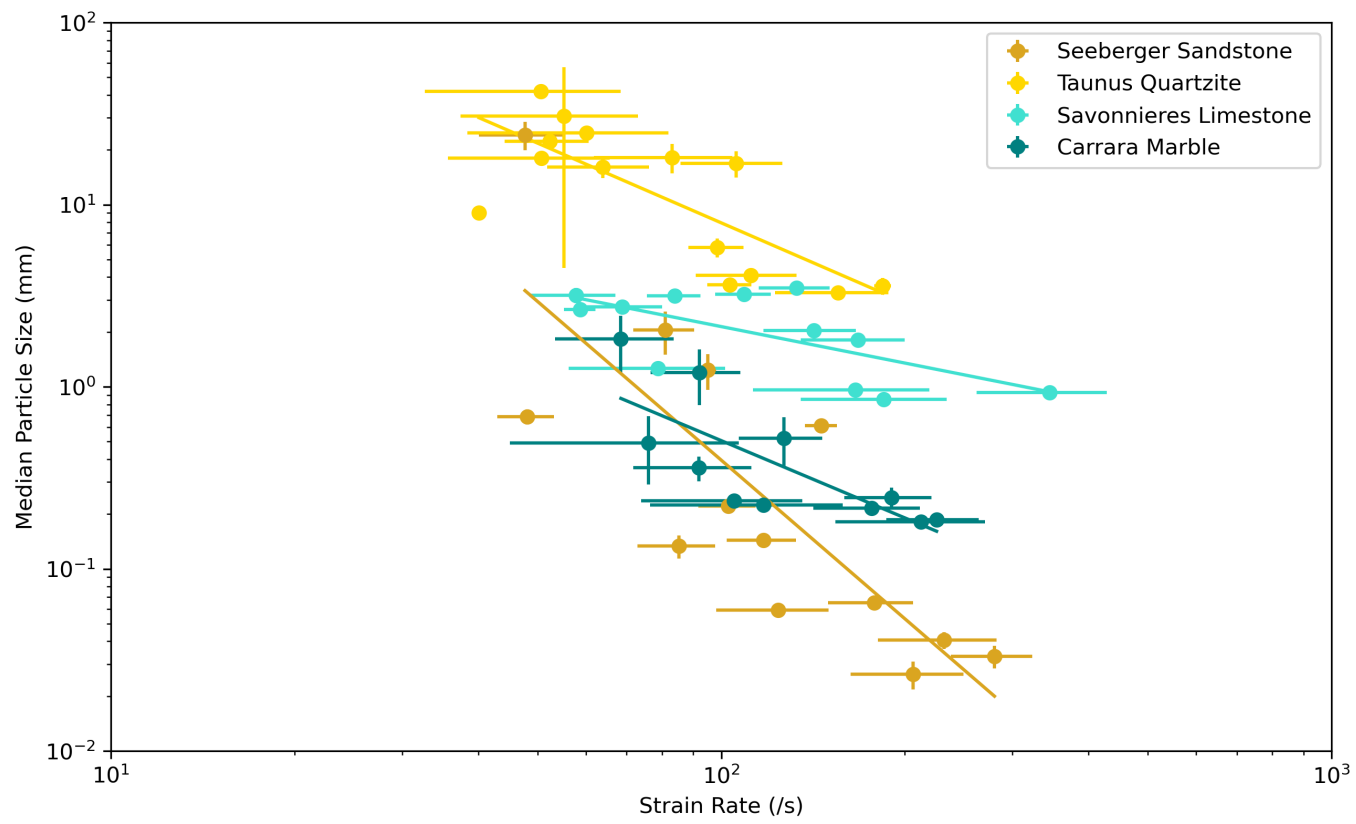

Figure 4. Median fragment size variation with strain rate. $x$ - and $y$ - uncertainties are shown for all points where the uncertainty bars are larger than the size of the point. 


\subsection{Fragment Shape Distributions}

Overall, the shape distributions of fragments do not vary as functions of strain rate or with lithology (Figures 5 and 6). For the fragments larger than $2 \mathrm{~mm}$ and across all lithologies, the average circularity is $0.733 \pm 0.087$ and the average axial ratio is $0.627 \pm 0.146$ (Table 2). No individual distribution, regardless of strain rate or lithology, is an outlier of these average values. For the fragments that range between 0.5 and $2 \mathrm{~mm}$ and across all lithologies, the average circularity is $0.598 \pm 0.180$ and the average axial ratio is $0.642 \pm 0.152$ (Table 2). The average circularity of these smaller fragments is less than the average circularity of the larger fragments while axial ratios remain similar, additionally the standard deviations of the distributions of these finer fragments is generally larger. We largely attribute these variations to differences in method between larger and smaller fragments (see Supplementary Material). However, we observe similar trends in the fragment shape distributions from sample to sample between the different fragment size fractions (Figures 5 and 6), demonstrating the overall robustness of the fragment shape analysis. 

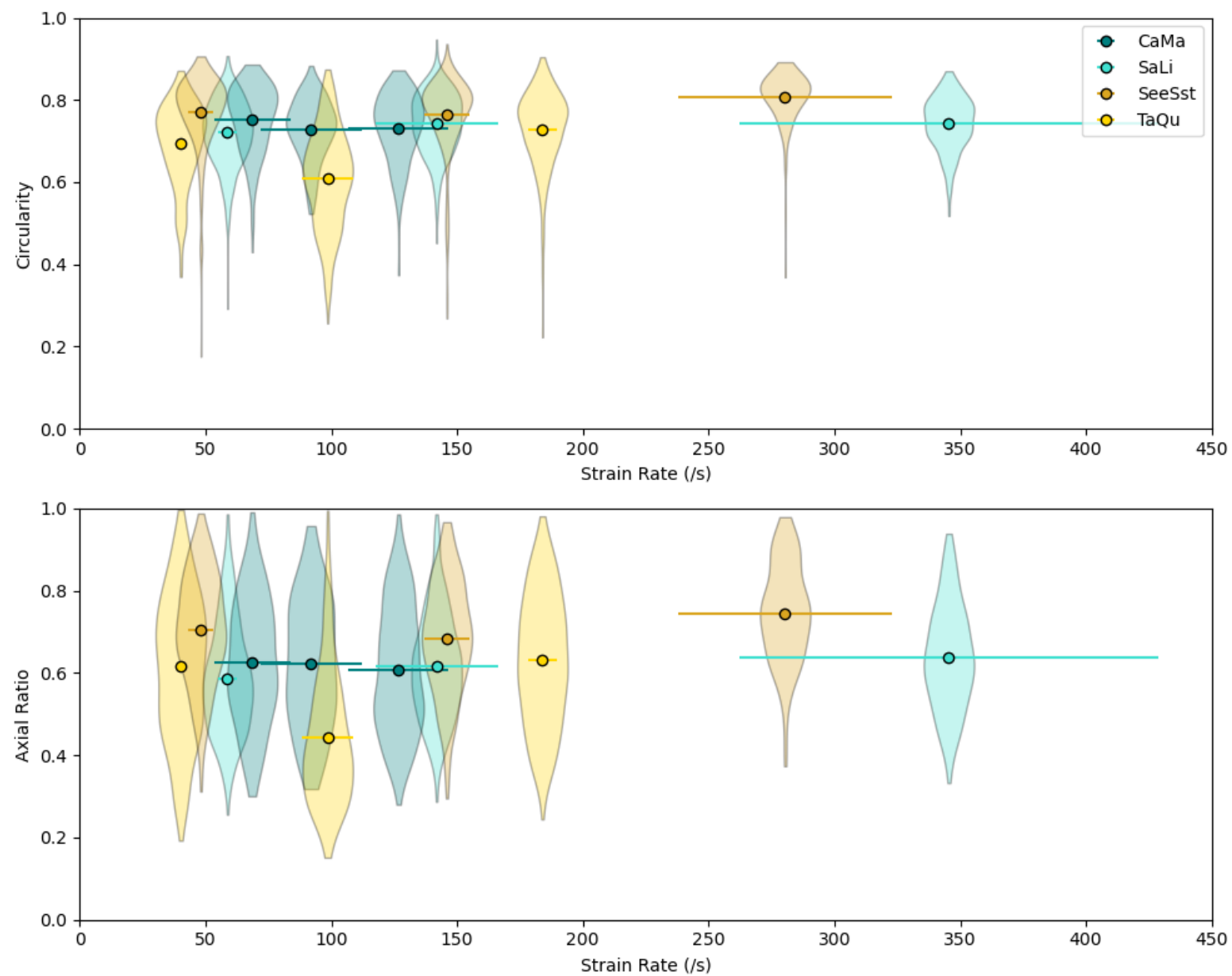

Figure 5. Fragment shape distributions for all fragments $>2 \mathrm{~mm}$ as a function of strain rate. Distributions of fragment shape (circularity and axial ratio) for each sample are shown as kernel density estimates. Each point shows the mean shape parameter plotted against the strain rate, where the x-error bar shows the uncertainty in the strain rate (see Supplementary Material for details). 

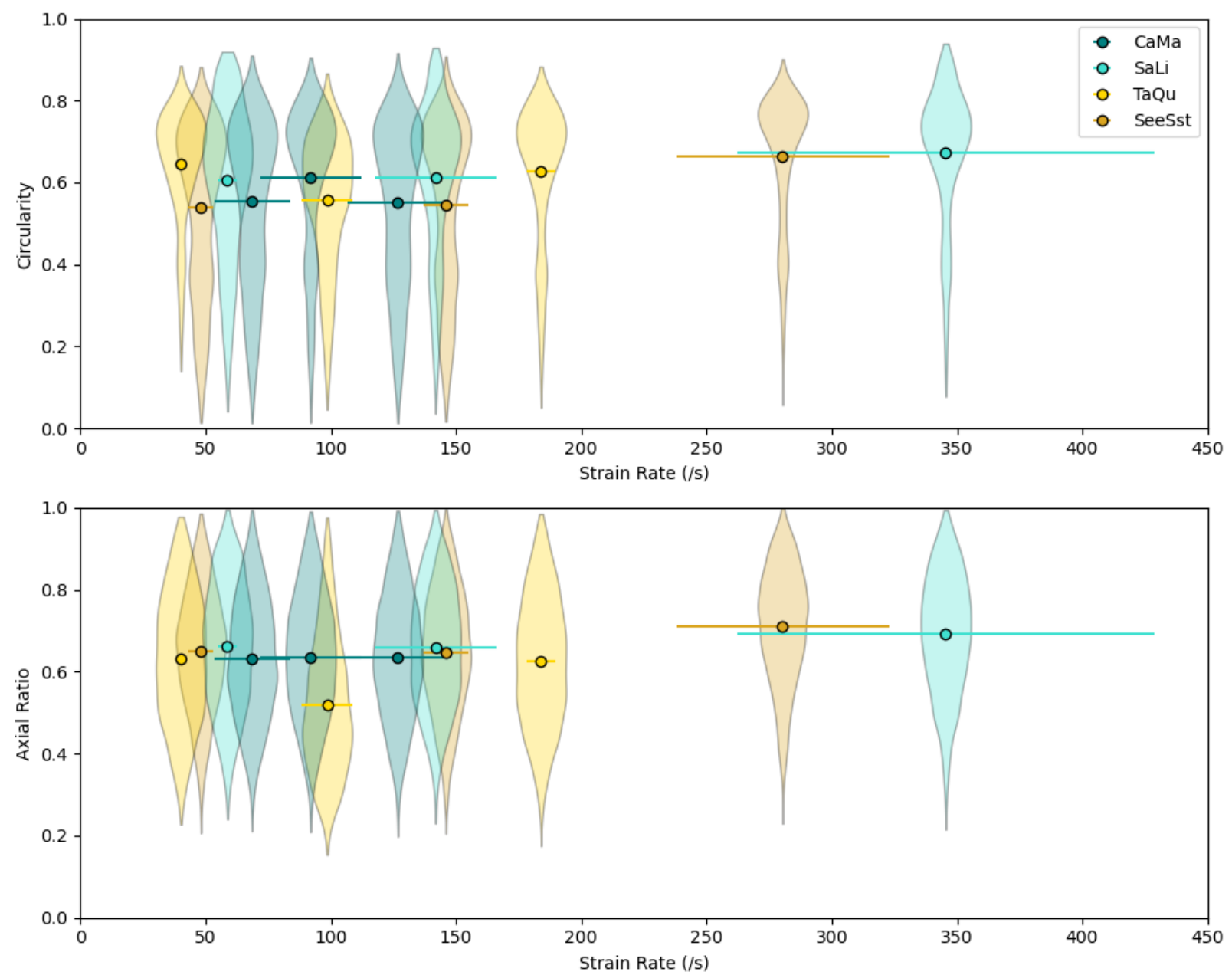

Figure 6. Fragment shape distributions for all fragments $0.5<\mathrm{x}<2 \mathrm{~mm}$ as a function of strain rate. Distributions of fragment shape (circularity and axial ratio) for each sample are shown as kernel density estimates. Each point shows the mean shape parameter plotted against the strain rate, where the x-error bar shows the uncertainty in the strain rate (see Supplementary Material for details). 
Table 2. Summary of fragment shape distributions of Seeberger Sandstone, Taunus Quartzite, Savonnières Limestone, and Carrara Marble organised by fragment size fraction.

\begin{tabular}{|c|c|c|c|c|}
\hline & \multicolumn{2}{|c|}{ Circularity } & \multicolumn{2}{|c|}{ Axial Ratio } \\
\hline Seeberger Sandstone & $\mu$ range $^{l}$ & Mean $\sigma^{l}$ & $\mu$ range ${ }^{l}$ & Mean $\sigma^{1}$ \\
\hline$s>2 m m$ & $0.765-0.805$ & 0.086 & $0.685-0.741$ & 0.131 \\
\hline $0.5<s<2 \mathrm{~mm}$ & $0.544-0.664$ & 0.189 & $0.649-0.712$ & 0.145 \\
\hline Taunus Quartzite & $\mu$ range ${ }^{l}$ & Mean $\sigma^{l}$ & $\mu$ range ${ }^{l}$ & Mean $\sigma^{1}$ \\
\hline$s>2 \mathrm{~mm}$ & $0.610-0.729$ & 0.106 & $0.444-0.631$ & 0.166 \\
\hline $0.5<s<2 \mathrm{~mm}$ & $0.556-0.646$ & 0.157 & $0.521-0.633$ & 0.161 \\
\hline Savonnières Limestone & $\mu$ range ${ }^{l}$ & Mean $\sigma^{l}$ & $\mu$ range ${ }^{l}$ & Mean $\sigma^{l}$ \\
\hline$s>2 \mathrm{~mm}$ & $0.720-0.743$ & 0.074 & $0.586-0.638$ & 0.131 \\
\hline $0.5<s<2 \mathrm{~mm}$ & $0.605-0.672$ & 0.180 & $0.659-0.692$ & 0.150 \\
\hline Carrara Marble & $\mu$ range $e^{l}$ & Mean $\sigma^{l}$ & $\mu$ range ${ }^{l}$ & Mean $\sigma^{l}$ \\
\hline $\mathrm{s}>2 \mathrm{~mm}$ & $0.727-0.753$ & 0.082 & $0.608-0.626$ & 0.155 \\
\hline $0.5<s<2 \mathrm{~mm}$ & $0.550-0.612$ & 0.194 & $0.633-0.636$ & 0.151 \\
\hline Average & Mean $\mu^{2}$ & Mean $\sigma^{2}$ & Mean $\mu^{2}$ & Mean $\sigma^{2}$ \\
\hline$s>2 \mathrm{~mm}$ & 0.733 & 0.087 & 0.627 & 0.146 \\
\hline $0.5<s<2 \mathrm{~mm}$ & 0.598 & 0.180 & 0.642 & 0.152 \\
\hline $\begin{array}{l}\mu=\text { mean value of a frag } \\
\sigma=\text { standard deviation o } \\
{ }^{1} \text { derived from all } 3 \text { distri } \\
{ }^{2} \text { derived from all } 12 \text { dist }\end{array}$ & $\begin{array}{l}\text { fize distrib } \\
\text { fragment size } \\
\text { tions for each }\end{array}$ & $\begin{array}{l}\text { tribution. } \\
\text { tology }\end{array}$ & & \\
\hline
\end{tabular}




\section{Discussion}

4.1 Strength and Characteristic Strain Rates

The quasi-static strengths of the Seeberger Sandstone, Taunus Quartzite, Savonnières Limestone, and Carrara Marble determined in this study are generally consistent with previous measurements of the same lithologies (Table 3). The only study of the same lithologies where measured strength values differ by more than $2 \sigma$ uncertainties is that of Millon et al. (2016); we note that Millon et al. used larger samples with greater aspect ratios (3:1) than our samples, which may be responsible for lower values of UCS (Hawkes and Mellor, 1970; Hawkins, 1998). 
Table 3. Comparison of uniaxial compressive strengths of the lithologies in this study with literature values.

\begin{tabular}{|c|c|c|c|c|}
\hline & $\begin{array}{l}\text { Seeberger } \\
\text { Sandstone }\end{array}$ & $\begin{array}{c}\text { Taunus } \\
\text { Quartzite }\end{array}$ & $\begin{array}{c}\text { Savonnières } \\
\text { Limestone }\end{array}$ & $\begin{array}{l}\text { Carrara } \\
\text { Marble }\end{array}$ \\
\hline This study & $55.8 \pm 3.6$ & $243.3 \pm 15.6$ & $18.6 \pm 1.5$ & $97.8 \pm 6.7$ \\
\hline (Poelchau et al., 2014) & $67.3 \pm 2.7$ & $292 \pm 39$ & - & - \\
\hline (Millon et al., 2016) & $42.3 \pm 2.4$ & - & $9.8 \pm 1.5$ & - \\
\hline (Zwiessler et al., 2017) & $60.4 \pm 4.6$ & - & - & $88.8 \pm 5.7$ \\
\hline (Van Stappen et al., 2019) & - & - & $\begin{array}{l}14.5 \pm 1.7 \text { (large }) \\
15.7 \pm 3.5(\text { small })\end{array}$ & - \\
\hline (Doan and Billi, 2011) & - & - & - & $\sim 100$ \\
\hline (Fredrich et al., 1989) & - & - & - & $100 *$ \\
\hline
\end{tabular}

*5 MPa confining stress 
Characteristic strain rates for rate dependency, whether defined strictly according to the scaling relationship of Kimberley et al. (2013) or more generally as the strain rate for the transition between quasi-static and dynamic deformation, are less widely reported than strength values. Dynamic strength data for the Seeberger Sandstone has been reported by Millon et al. (2016) and Zwiessler et al. (2017). Millon et al. (2016) did not directly report a characteristic rate but instead demonstrated dynamic increase factors (DIFs) between 3.6 and 5.3 at strain rates between 275 and $350 \mathrm{~s}^{-1}$; ultimately suggesting a characteristic strain rate (where at that rate, DIF is 2) that is less than $275 \mathrm{~s}^{-1}$ but greater than $\sim 10^{1} \mathrm{~s}^{-1}$. Zwiessler et al. (2017), on the other hand state the characteristic rate of the Seeberger Sandstone to be $170 \mathrm{~s}^{-1}$. Both of these studies appear to demonstrate lower values of characteristic strain rate than reported here, however we note that our results are based on a considerably larger data set and that our results provide quantified, and quite large, statistical uncertainties. To our knowledge, dynamic strength properties of the Taunus Quartzite have never been reported. Millon et al. (2016) also investigated the dynamic strength of the Savonnières Limestone. They found DIFs of 4.3-4.9 over strain rates from 345-515 $\mathrm{s}^{-1}$; suggesting a characteristic strain rate less than 345 but greater than $\sim 10^{1} \mathrm{~s}^{-1}$. Again, this is lower than the value of the characteristic rate reported in this study, however again, our study is based on a larger data set, and provides more constraint on the value of the characteristic strain rate. Furthermore, we note that our study is consistent with the results of Millon et al. (2016) in that the characteristic rates of both the Seeberger Sandstone and Savonnières Limestone are similar, being within uncertainties of each other. Finally, the characteristic strain rate of the Carrara Marble has been reported by Zwiessler et al. (2017) as $65 \mathrm{~s}^{-1}$. Additionally, Zou and Wong (2016) reported DIFs between 4.0 - 7.0 at strain rates between $100-600 \mathrm{~s}^{-1}$, suggesting a characteristic strain rate between 10 and $100 \mathrm{~s}^{-1}$. Our value for the characteristic strain rate of the Carrara Marble is greater than both Zwiessler et al. (2017) and Zou and Wong (2016) suggest, however, our results are consistent with the results of Zwiessler et al. (2017) in that the characteristic rate of the Carrara Marble is significantly less than the characteristic rate of the Seeberger Sandstone. Additionally, in a study on the dynamic deformation of the Carrara Marble, Doan and Billi (2011) found a transition from splitting to pulverization at peak strain rates of $\sim 100 \mathrm{~s}^{-1}$. However, their results show a curious lack of systematic increase in strength between peak rates of $\sim 50-250 \mathrm{~s}^{-1}$.

Other studies of dynamic strength in sedimentary and metamorphic rocks are generally consistent with the results of our study. Green et al. (1972) conducted one of the earliest studies 
on the dynamic strength properties of rocks and found a transition to dynamic behaviour in Solnhofen Limestone at $\sim 10^{2} \mathrm{~s}^{-1}$. Howe et al. (1974) found dynamic strength increases in the anisotropic Yule Marble at rates $>10 \mathrm{~s}^{-1}$. In a study on the Berea Sandstone and Indiana Limestone, Blanton (1981) demonstrated a lack of dynamic strength effects at strain rates up to $10 \mathrm{~s}^{-1}$. On the same limestone, Frew et al. (2001) found DIFs of up to 1.7 at rates of $\sim 100 \mathrm{~s}^{-1}$. Rosakis (1999) reported dynamic strength properties of Dionysus-Pentalicon Marble (see Bhat et al., 2012), demonstrating DIFs of 2 at $\sim 400 \mathrm{~s}^{-1}$. In sandstones, Alam et al. (2015) found DIFs up to $\sim 1.8$ at strain rates up to $\sim 1 \mathrm{~s}^{-1}$ in an investigation of the Kota Sandstone while Liu et al. (2012) conducted experiments on Qinling Sandstone at rates between 50-100 s $\mathrm{s}^{-1}$ and found DIFs between 1.6 and 3.2; suggesting a characteristic strain rate of $\sim 60 \mathrm{~s}^{-1}$. Most recently, Fondriest et al. (2017) investigated the Mendola Dolostone and found the onset of pulverisation at rates of $\sim 120 \mathrm{~s}^{-1}$, albeit with limited dynamic strength increase between 40 and $300 \mathrm{~s}^{-1}$.

Our results show that the characteristic strain rates of the Seeberger Sandstone, Taunus Quartzite, and Savonnières Limestone, with values of $322 \pm 92,280 \pm 92$, and $241 \pm 78$ respectively, are all within uncertainty of each other (Table 1). In a previous study, we reported the characteristic strain rates of felsic crystalline rocks; a granite and a transversely isotropic gneiss (Rae et al., 2020), to be within uncertainty of each other (and independent of anisotropy) with an average value of $229 \pm 81 \mathrm{~s}^{-1}$, remarkably similar to the characteristic rates of the Seeberger Sandstone, Taunus Quartzite, and Savonnières Limestone. This suggests that lithological variability of characteristic strain rate is minor or even negligible for rocky materials, particularly given the large uncertainties that arise as a result of inter-sample variability, in addition to the challenges of defining a precise and accurate representative strain rates for the SHPB and other dynamic mechanical testing techniques (Aben et al., 2017; Ramesh et al., 2015; Supplementary

\section{Material).}

The Carrara Marble, with a characteristic rate of $144 \pm 33$, is the only lithology we have investigated to have a significantly different value of characteristic strain rate. By the consideration of characteristic length and time scales, Kimberley et al. (2013) suggested that the characteristic 
strain rate in their scaling relationship can be related to mechanical and microstructural properties of the material:

$$
\dot{\varepsilon}_{0} \propto \frac{v_{p}}{\bar{s}} \frac{K_{I C}}{E} \eta^{1 / 4},(5)
$$

where $\boldsymbol{v}_{\boldsymbol{p}}$ is the p-wave speed, $\overline{\boldsymbol{s}}$ is the average flaw size, $\boldsymbol{K}_{\boldsymbol{I} \boldsymbol{C}}$ is the mode-I fracture toughness, $\boldsymbol{E}$ is the elastic modulus, and $\boldsymbol{\eta}$ is the flaw density. By this consideration, the Carrara Marble must either possess comparatively low values of $\boldsymbol{v}_{\boldsymbol{p}}, \boldsymbol{K}_{\boldsymbol{I C}}$, or $\boldsymbol{\eta}$, or large values of $\overline{\boldsymbol{s}}$ or $\boldsymbol{E}$. Based on the elastic properties determined in this study, the wave speed of the Carrara Marble is actually significantly greater than that of the other lithologies; while the elastic modulus, though large is comparatively similar to the other non-porous lithology, i.e., the Taunus Quartzite. The mode-I fracture toughness of the Carrara Marble has been measured by Atkinson (1979) and Meredith et al. (1984) as 0.64 and $0.87 \mathrm{MPa} \mathrm{m}{ }^{1 / 2}$, respectively. Mode-I fracture toughness for the other lithologies in this study have not been determined, however in comparison to literature values for sandstones, quartzites, and limestones generally (Table 4), the fracture toughness of the Carrara Marble is low, though not by a large enough factor to fully account for the reduced characteristic strain rate. The microstructural properties of flaw size and flaw density are extremely challenging to measure within a real rock (Housen and Holsapple, 1999), and therefore, it may be the case that the Carrara Marble simply has an unusual distribution of flaws to explain the discrepancy in characteristic strain rate. Nevertheless, the scaling relationship of Kimberley et al. (2013) assumes that the mode-I fracture toughness is a constant value; but fracture toughness is known to increase as a function of strain rate (Bhat et al., 2012; Ravi-Chandar and Knauss, 1984a; Zhang and Zhao, 2014). Consequently, the behaviour of the Carrara Marble may be a consequence of a decreased sensitivity of fracture toughness with strain rate in comparison to other rocks. 
Table 4: Literature values of Mode-I fracture toughness $\left(\mathrm{K}_{\mathrm{IC}}\right)$

\begin{tabular}{|c|c|c|}
\hline & Notes & $K_{I C}\left(M P a m^{1 / 2}\right)$ \\
\hline Sandstone & $\begin{array}{l}\text { Average of critical } K_{I C} \text { values from } \\
\text { Atkinson and Meredith }(1987)(n=6)\end{array}$ & $1.08 \pm 0.85$ \\
\hline Quartzite & $\begin{array}{l}\text { Average of critical } K_{I C} \text { values from } \\
\text { Atkinson and Meredith (1987) }(n=3)\end{array}$ & $1.68 \pm 0.39$ \\
\hline Limestone & $\begin{array}{l}\text { Average of critical } K_{I C} \text { values from } \\
\text { Atkinson and Meredith }(1987)(n=5)\end{array}$ & $1.11 \pm 0.33$ \\
\hline Carrara Marble & Atkinson (1979) and Meredith et al. (1984) & $0.76 \pm 0.16$ \\
\hline Granite & $\begin{array}{c}\text { Average of critical KIC values from } \\
\text { Atkinson and Meredith (1987) }(\mathrm{n}=63) \text {. } \\
\text { Used in Rae et al. (2020) }\end{array}$ & $1.73 \pm 0.59$ \\
\hline Gneiss (Parallel Foliation) & Used in Rae et al. (2020) & $1.56 \pm 0.53$ \\
\hline Gneiss (Perpendicular Foliation) & Used in Rae et al. (2020) & $1.90 \pm 0.65$ \\
\hline
\end{tabular}




\subsection{Fragment size - An Empirical Compressive Fragmentation Relationship}

Our results demonstrate the general relationship that increasing strain rate results in finer fragmentation under uniaxial compression. This observation is in agreement with a large number of previous studies (e.g. Barber and Griffith, 2017; Doan and Billi, 2011; Doan and d'Hour, 2012; Doan and Gary, 2009; Fondriest et al., 2017; Ghaffari et al., 2019; Hogan et al., 2016, 2012; Li et al., 2018; Millon et al., 2016; Rae et al., 2020; Yao et al., 2020; Yuan et al., 2011). Specific comparison of our fragmentation results with many of these studies is challenging for a variety of reasons. Firstly, fragment size distributions can be characterised by either mass or by number, converting number-size to mass-size distributions and vice versa is non-trivial. Secondly, even with the same type of distribution, its shape will depend on the method used to obtain that distribution (e.g. sieving, sedimentation, laser diffraction). Finally, there is no single common method of determining the "characteristic" size of a fragment size distribution. We arbitrarily chose to use the median of the fragment mass-size distribution (also known as D50) as the "characteristic" size of each distribution.

Despite these complexities, we find that the fragmentation behaviour of the Taunus Quartzite is very similar to the behaviour of felsic crystalline rocks (Rae et al., 2020), producing average fragment sizes of 40-1 mm at strain rates of 30-300 s-1 (Figure 4). Somewhat expectedly, the Seeberger Sandstone produces considerably finer fragments at equivalent strain rates, which we attribute to the relative ease of fracturing and separation of grains in a porous material. By comparison, the Savonnières Limestone produces coarser fragments than the Seeberger Sandstone but finer fragments than the Taunus Quartzite and other non-porous crystalline rocks (Figure 4). We suggest that this may be a consequence of the relative grain sizes of the lithologies; the texture of the Savonnières Limestone is dominated by $0.5-1 \mathrm{~mm}$ diameter ooids, while the Seeberger Sandstone has an average grain size of $\sim 0.1 \mathrm{~mm}$. Our results on the fragmentation of Seeberger Sandstone and Savonnières Limestone can be compared to the results of Millon et al. (2016) who report fragment size distributions with D50 values from 19.9-1.6 $\mathrm{mm}$ at strain rates between 20 and $345 \mathrm{~s}^{-1}$ respectively for the Seeberger Sandstone, and D50 values between 21.4 and $0.46 \mathrm{~mm}$ at strain rates between 20 and $515 \mathrm{~s}^{-1}$ respectively for the Savonnières Limestone. These fragment sizes are generally consistent with the results of our study except for the average fragment size of the Seeberger Sandstone at large strain rates where we produced considerably finer fragments. In 
a study of the dynamic failure properties of the Carrara Marble, Doan and Billi (2011) found that pulverisation of marble was "easier" than pulverisation in granite. Our study is consistent with this observation, where, at the same strain rate, the Carrara Marble produces fragments at least one order of magnitude finer than the fragmentation of felsic crystalline rocks reported by Rae et al. (2020) and the quartzite of this study. The Carrara Marble even produces finer fragments than the Savonnières Limestone, which may be a consequence of its finer grain size.

A number of models have been proposed to determine average fragment size as a function of strain rate (Glenn and Chudnovsky, 1986; Grady, 1982; Levy and Molinari, 2010; Zhou et al., 2006a, 2006b). These models are principally concerned with tensile fragmentation of an expanding shell. While each model has important differences, all models predict that in the dynamic regime, fragment size is an inverse power law function of strain rate with an exponent of $2 / 3$, a value that arises as a consequence of the assumption of equilibrium conversion of the kinetic energy released in fragmentation to fracture surface energy (Grady, 1982). All of the rocks in this study demonstrate an inverse power law relation between median fragment size under uniaxial compressive failure and strain rate (Figure 4). However, the exponents of those power-laws vary, depending on lithology, between $0.65+/-0.23$ and $2.90+/-0.63$ (Table 1). Ghaffari et al. (2019) also reported an inverse power-law relationship between fragment size and strain rate in uniaxial compression in Westerly Granite, however their exponent of 0.42 is considerably lower than a value of $2 / 3$, unlike our results which produced exponents that were generally greater.

Tensile failure, as modelled in the expanding shell problem, is fundamentally different from compressive failure (Jaeger et al., 2007). The creation, activation, and growth of internal defects that occurs during compressive failure can make a material quite different from its pristine condition (Hogan et al., 2016), and large amounts of strain energy can be stored in brittle materials in compression which, when released, can generate very fine fragments (Ramesh et al., 2015). Consequently, compressive fragmentation cannot be directly compared to tensile fragmentation models. Hogan et al. (2016) and Ramesh et al. (2015) have developed a method to convert compressive strain rates to equivalent tensile strain rates such that compressive failure could be compared to tensile fragmentation models. In a previous study (Rae et al., 2020), we found that applying this method did result in fragmentation from multiple lithologies collapsing onto a single power-law relationship, however the exponent of that relationship remained significantly different 
from the expected exponent of $2 / 3$. The results presented here could be analysed with the same method to produce a similar result; however, we have decided to take a more phenomenological approach and derive a simple empirical relationship between strain rate and fragment size. To achieve this, we first normalise the compressive strain rate by the characteristic strain rate for each lithology. Then we attempted to find a normalisation factor for the average fragment size that caused the results to collapse onto a single power law. Noting that the method of Hogan et al. (2016) and Ramesh et al. (2015) achieved the collapse of the data to a single power-law, we decided to attempt a normalisation factor akin to the characteristic length used in their method. That characteristic length, $s_{0}$, is determined by considering the characteristic time, $\mathrm{t}_{0}$, for the growth of a cohesive crack under external loading and the sound velocity of the material (Camacho and Ortiz, 1996; Drugan, 2001):

$$
s_{0}=v_{p} t_{0}=\frac{K_{I C} C^{2}}{2 \sigma_{t}^{2}},(\mathbf{6})
$$

where $\sigma_{t}$ is the tensile strength of the material. Noting that the tensile strength of rocks is typically some constant fraction of the compressive strength (e.g. Hogan et al., 2016), we reduce the characteristic length scale to remove the constant terms, i.e.:

$$
s_{0}=\frac{K_{I C} C^{2}}{\sigma_{0}^{2}} \cdot(7)
$$

While $K_{I C}$ values for the Carrara Marble have been determined experimentally (Atkinson, 1979; Meredith et al., 1984). $K_{I C}$ is unknown for the other lithologies, instead, we take the average value of $K_{I C}$ from similar lithologies and include the effect of considerably larger uncertainties (Table 4).

Normalisation of the strain rates and fragment sizes for all the experiments in this study and the experimental results of Rae et al. (2020) are shown on Figure 7. We notice that this normalisation results in the collapse of all non-porous lithologies to a single inverse power-law relation, and the porous lithologies (Seeberger Sandstone, $\varphi=20.0 \pm 0.8 \%$; Savonnières 
Limeston, $\varphi=31.4 \pm 1.1 \%$ ) to a parallel trending inverse power-law. The general form of this power law is expressed as:

$$
\frac{\bar{s}}{s_{0}}=k{\frac{\dot{\varepsilon}}{\dot{\varepsilon}_{0}}}^{-\mu}
$$

We fit the data for non-porous and porous rocks using non-linear least squares fitting in log-log space to determine that, for non-porous rocks, the exponent, $\mu$, is $1.93 \pm 0.14$, and the constant $k$ is $\mathbf{1 2 .} \mathbf{2}_{-\mathbf{1 . 6 7}}^{\mathbf{+ 1 . 9 3}}$. The power law for porous rocks has an exponent, $\mu$, of $1.78 \pm 0.40$, and a constant, $k$, of $\mathbf{0 . 1 3}+\mathbf{0 . 0 4}$ (Table 5). The exponents are within $1 \sigma$ uncertainty of each other, while the constants are significantly different, indicating that the constant $k$, is likely to be a function of porosity, or some mechanical or microstructural property closely related to porosity (e.g. flaw density, flaw size, etc.). However, in the absence of a wider variety of tested porous rocks, we are unable to speculate further on the nature of the dependency of $k$ on porosity. We emphasise that our relationship for porous rocks is only appropriate for porosities between $\sim 20-30 \%$; less porous rocks are likely to follow trends with intermediate values of $k$. 
Table 5. Empirical fragmentation relationship parameters.

\begin{tabular}{l|cc}
\multicolumn{2}{c}{$k$} & $\mu$ \\
\hline Non-Porous Rocks & $12.2_{-1.67}^{+1.93}$ & $1.93 \pm 0.14$ \\
Porous Rocks ( 20-30\%) & $0.13_{-0.04}^{+0.07}$ & $1.78 \pm 0.40$
\end{tabular}

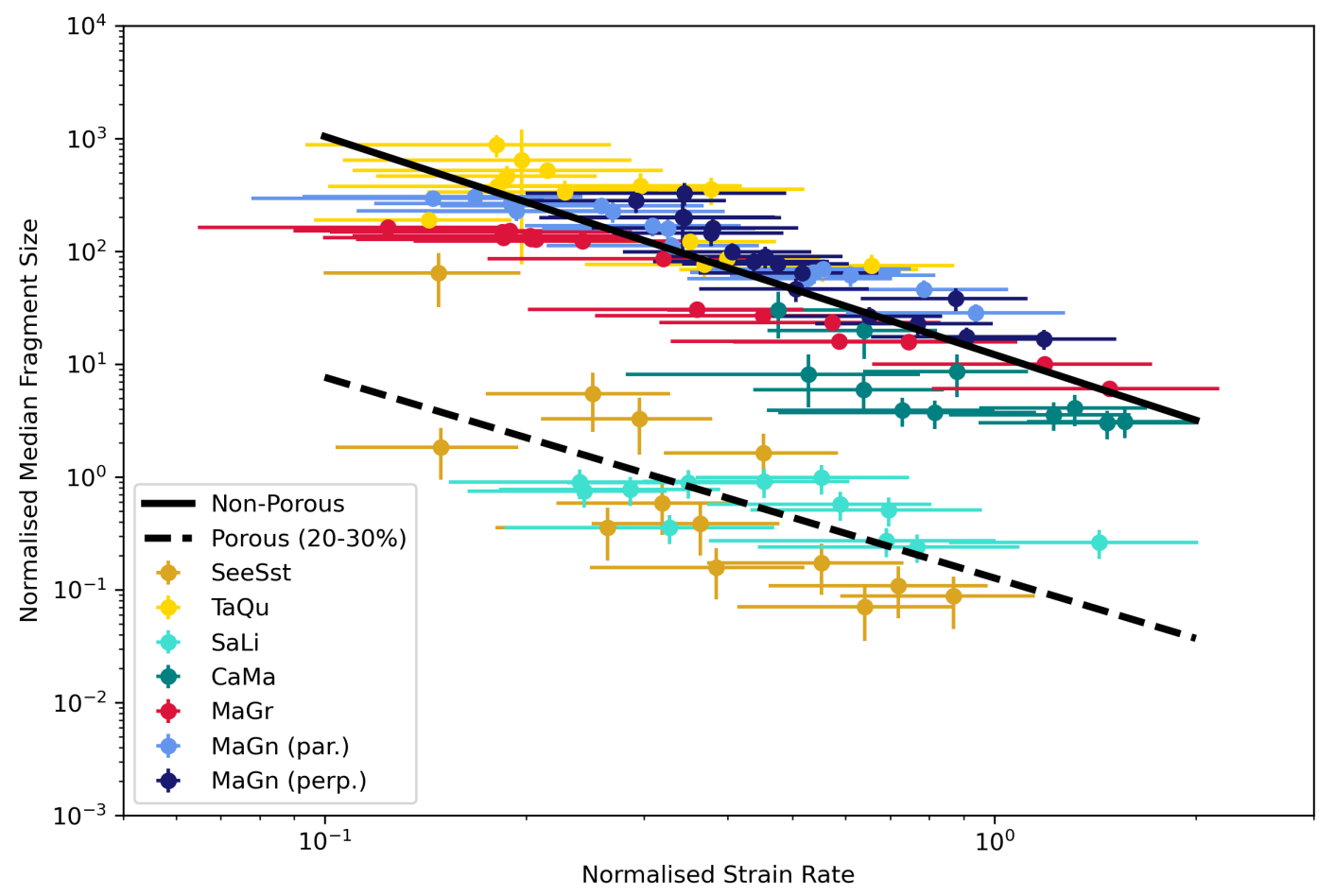

Figure 7. Scaled empirical fragmentation relationships for non-porous and porous rocks. Nonporous rocks are Taunus Quartzite $(\mathrm{TaQu})$, Carrara Marble (CaMa), and the felsic crystalline rocks presented in (Rae et al., 2020); Malsburg Granite (MaGr) and Maggia Gneiss (MaGn; where the foliation was oriented parallel and perpendicular to the axis of compression). Porous rocks are Seeberger Sandstone (SeeSst) and Savonnières Limestone (SaLi). 


\subsection{Fragment shapes}

Our results demonstrate that fragment shape is independent of both strain rate and lithology (Figures 5 and 6). For all of the lithologies in this study, average fragment circularity and axial ratios at all strain rates are both $\sim 0.6$. Our results therefore suggest that fragment shape cannot be used as a fingerprint for the conditions at which deformation and, more specifically, fragmentation occurred. Nevertheless, we note that our experiments were only conducted under uniaxial compression; it remains to be seen whether fragment shape in dynamic failure is dependent on the state of stress, whether simply confined or under truly triaxial conditions.

To understand why fragment shape may be independent of strain rate during dynamic fragmentation, we consider the geometric fragmentation of a unit area/volume. At low strain rates, an area/volume will be fragmented by a small number of fractures, producing a small number of large fragments. At high strain rates, the area/volume will be fragmented by a large number of fractures, producing a large number of small fragments. The exact distribution of fragment sizes is fundamentally linked to the method by which fractures are constructed (Grady and Kipp, 1985). Here, we implement a variety of construction algorithms to randomly fragment a two-dimensional area with the aim of seeing how fragment shape changes as a function of the number of fractures (i.e. strain rate). We chose three geometric fragmentation construction algorithms as described by Grady and Kipp (1985): Random Lines, Random Line Segments, and Voronoi Segmentation.

The Random Lines algorithm is the simplest of the three. Here, a specified number of randomly distributed points are placed within a unit area. Each point is then assigned a random orientation (between 0 and 180), and a fracture (straight line) is extended from that point such that it extends from one edge of the unit area to another, passing through the point at the assigned orientation. This process is conducted for all points simultaneously. The Random Line Segments algorithm has several similarities to the Random Lines algorithm but is more complex, and realistic. Here, each fracture is added sequentially with the condition that the fracture must terminate against any pre-existing fracture. Voronoi segmentation is conceptually rather different to the previous algorithms but also produces random fragmentation of a unit area. Here, a specified number of random points ("seeds") are chosen, and the unit area is divided into segments which contain all of the locations closest to a single seed. For each algorithm, 10 images were generated, each with 
varying numbers of lines or seeds. Those images were then analysed to characterise the shapes (circularity and axial ratio) of the fragments, excluding those at the edge of the unit area, as a function of the number of lines/seeds.

With the Random Lines algorithm, we find that axial ratio is constant as a function of the number of lines while circularity increases (Figure 8a). With the Random Line Segments and Voronoi algorithms, we found no variation of either circularity or axial ratio with increasing number of lines/seeds (Figures 8b and 8c). Of the three algorithms, Voronoi segmentation achieves the closest match to our experimental results with average circularities of $\sim 0.7$ and average axial ratios of $\sim 0.6$. We emphasise though, that none of the implemented algorithms are particularly representative of the real process of dynamic fragmentation as they ignore all of the physical and dynamic processes of fracture nucleation and growth. Nevertheless, they demonstrate that uniform fragment shapes as a function of strain rate is a consequence of fragmentation as a stochastic process where the growth of fractures is limited by the presence of other growing fractures. A further implication of our results is that the behaviour of fractures did not change over the conditions explored in our study, i.e. uniaxial compression at rates between $\sim 30$ and $300 \mathrm{~s}^{-1}$. Experimental studies have shown that fractures, particularly Mode-I fractures, in the dynamic regime may bifurcate or branch under increasing loading rates (Ravi-Chandar and Knauss, 1984b; Zhang and Zhao, 2014; Zhang et al., 1999), this would be expected to lead to the production of more elongate and less circular fragments as a function of increasing rate. However, our results show no variation of fragment shape in common with the simplified geometric models of fragmentation where each fracture behaves the same, regardless of the "strain rate". 

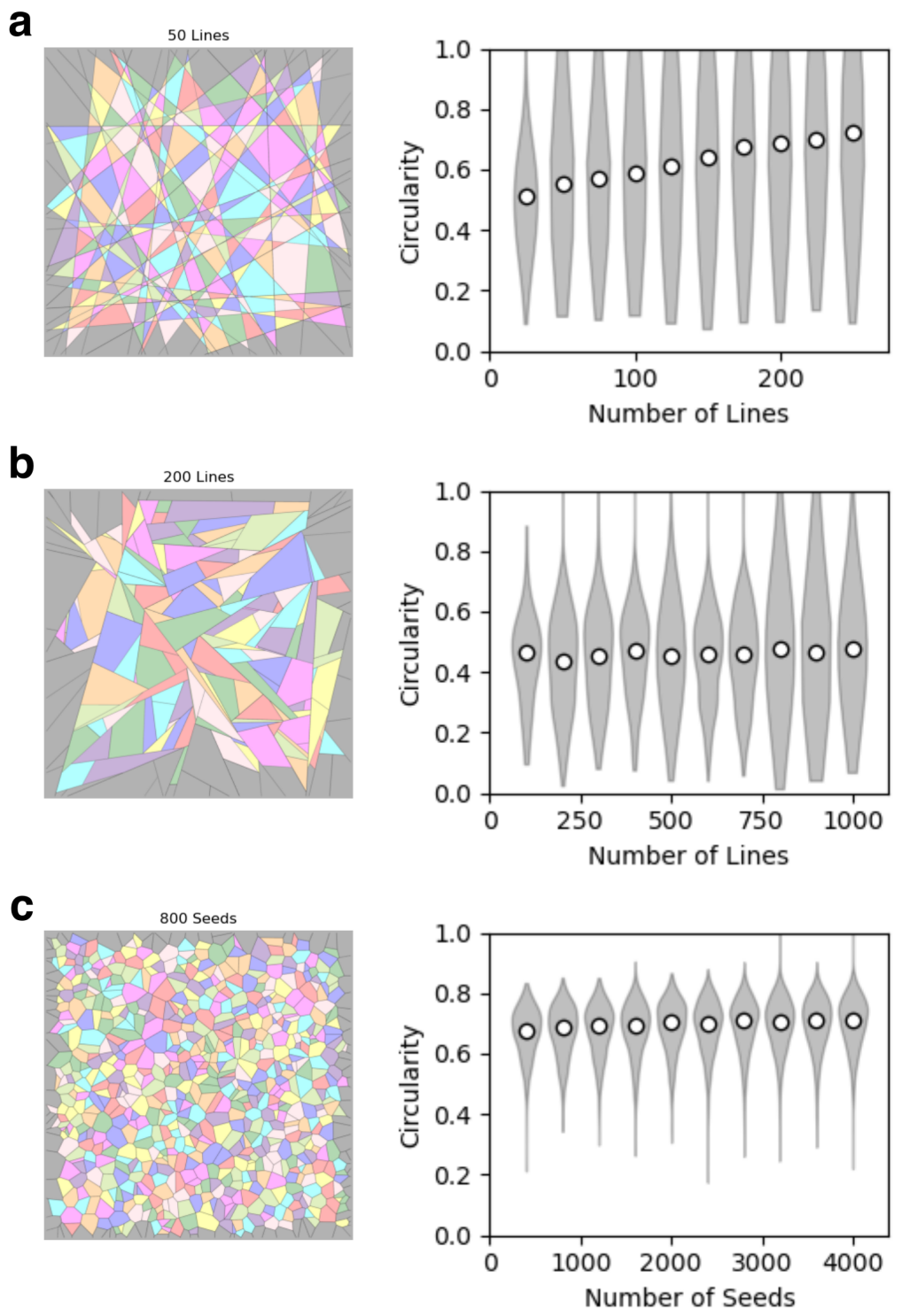
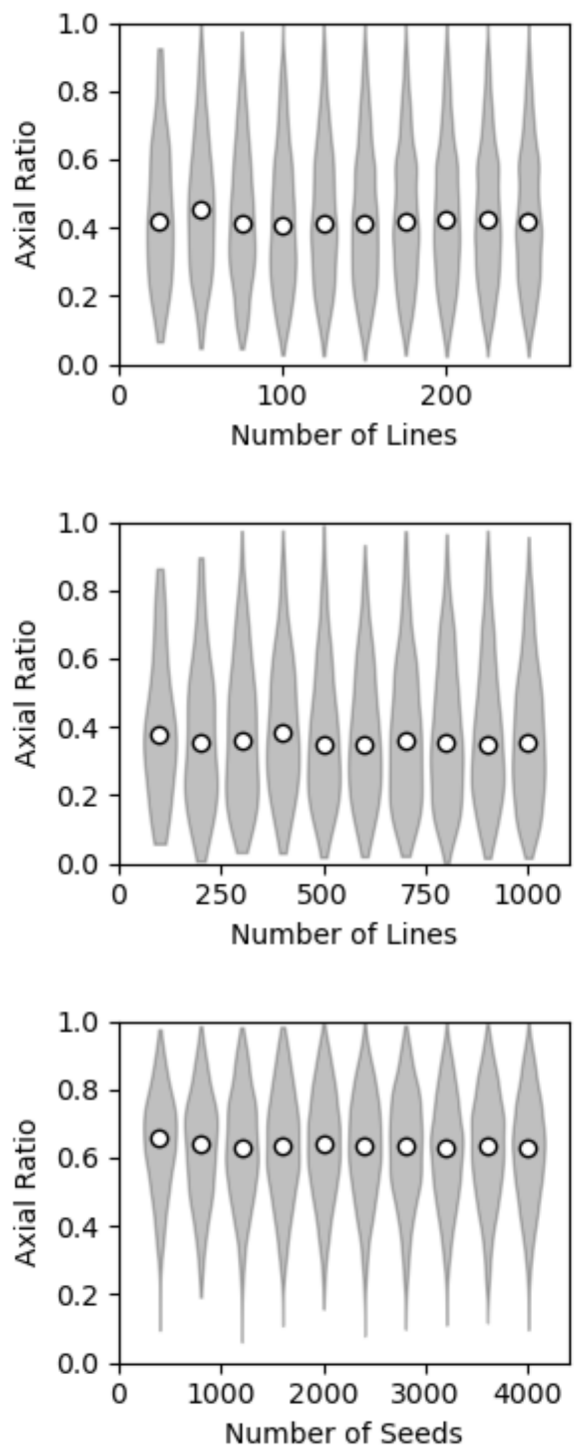

Figure 8. Examples of geometric fragmentation algorithms and the shapes of fragments as functions of the number of lines/seeds. An increase in the number of lines/seeds is analogous to increasing strain rate, compare with Figures 5 and 6. a) Random Lines, b) Random Line Segments, c) Voronoi Segmentation. 


\section{Conclusions}

In this study, we have shown that the characteristic strain rates for rate-dependent strength and brittle behaviour under uniaxial compressive loading in sandstone, quartzite, limestone, and marble ranges between $\sim 144-322 \mathrm{~s}^{-1}$. The degree of fragmentation increases with strain rate over the full range of dynamic rates investigated $\left(\sim 30-350 \mathrm{~s}^{-1}\right)$. Our results demonstrate that compressive fragmentation cannot be described by tensile fragmentation models, and instead we describe an empirical fragmentation relationship for uniaxial compression that describes average fragment size as a function of strain rate. This relation has the form of an inverse power-law with an exponent of $1.93+/-0.14$ and a constant that varies with porosity, or some material property correlated with porosity. The applicability of this relation at strain rates at greater or lesser strain rates remains to be seen. The results of our study also demonstrate that fragment shape during dynamic failure is independent of strain rate and lithology, at least for uniaxial compression and the homogeneous lithologies investigated here.

The clear implication of this study is that fragment size may be used as a diagnostic indicator of the strain rate at failure while fragment shape cannot be used. Nevertheless, we note that our experiments were conducted under uniaxial conditions, confinement or truly triaxial stress states during fragmentation may cause significant changes to the process of dynamic fragmentation (Liu et al., 2019; Liu and Zhao, 2021; Yuan et al., 2011) and the fragmentation relation described here. Furthermore, our experiments were conducted on intact rocks, it remains unclear how fragments generated by repeated low-rate events (Aben et al., 2016) can be differentiated from single high-rate events.

\section{Acknowledgments and Data Availability}

The authors wish to acknowledge Herbert Ickler and Gordon Mette for preparation of samples. Tony Kern is thanked for assistance in sample preparation and UCS experiments. Additionally, Sebastian Hess of the Ernst-Mach Institute is thanked for technical assistance with the SHPB. Lennart Fischer is thanked for the instruction and use of the PICAT imaging system. All data presented within this publication can be found at https://github.com/ASprae/DynamicStrength-and-Fragmentation. This work was funded by DFG Project KE 732/27-1. 


\section{References}

Aben, F.M., Doan, M.-L., Gratier, J.-P., Renard, F., 2017. Coseismic Damage Generation and Pulverization in Fault Zones, in: Fault Zone Dynamic Processes. American Geophysical Union (AGU), pp. 47-80. https://doi.org/10.1002/9781119156895.ch4

Aben, F.M., Doan, M.-L., Mitchell, T.M., Toussaint, R., Reuschlé, T., Fondriest, M., Gratier, J.P., Renard, F., 2016. Dynamic fracturing by successive coseismic loadings leads to pulverization in active fault zones. Journal of Geophysical Research: Solid Earth 121, 2338-2360. https://doi.org/10.1002/2015JB012542

Agosta, F., Aydin, A., 2006. Architecture and deformation mechanism of a basin-bounding normal fault in Mesozoic platform carbonates, central Italy. Journal of Structural Geology 28, 1445-1467. https://doi.org/10.1016/j.jsg.2006.04.006

Alam, Md.S., Chakraborty, T., Matsagar, V., Rao, K.S., Sharma, P., Singh, M., 2015. Characterization of Kota Sandstone Under Different Strain Rates in Uniaxial Loading. Geotech Geol Eng 33, 143-152. https://doi.org/10.1007/s10706-014-9810-3

Atkinson, B.K., 1979. Fracture toughness of Tennessee Sandstone and Carrara Marble using the double torsion testing method. International Journal of Rock Mechanics and Mining Sciences \& Geomechanics Abstracts 16, 49-53. https://doi.org/10.1016/01489062(79)90774-5

Atkinson, B.K., Meredith, P.G., 1987. Experimental fracture mechanics data for rocks and minerals, in: Atkinson, B.K. (Ed.), Fracture Mechanics of Rock. Academic Press, London, pp. 477-525.

Barber, T., Griffith, W.A., 2017. Experimental constraints on dynamic fragmentation as a dissipative process during seismic slip. Philosophical Transactions of the Royal Society A: Mathematical, Physical and Engineering Sciences 375, 20160002. https://doi.org/10.1098/rsta.2016.0002

Bhat, H.S., Rosakis, A.J., Sammis, C.G., 2012. A Micromechanics Based Constitutive Model for Brittle Failure at High Strain Rates. J. Appl. Mech 79. https://doi.org/10.1115/1.4005897

Blanton, T.L., 1981. Effect of strain rates from 10-2 to $10 \mathrm{sec}-1$ in triaxial compression tests on three rocks. International Journal of Rock Mechanics and Mining Sciences \& Geomechanics Abstracts 18, 47-62. https://doi.org/10.1016/0148-9062(81)90265-5

Brune, J.N., Brown, S., Johnson, P.A., 1993. Rupture mechanism and interface separation in foam rubber models of earthquakes: a possible solution to the heat flow paradox and the paradox of large overthrusts. Tectonophysics, New horizons in strong motion: Seismic studies and engineering practice 218, 59-67. https://doi.org/10.1016/00401951(93)90259-M

Camacho, G.T., Ortiz, M., 1996. Computational modelling of impact damage in brittle materials. International Journal of Solids and Structures 33, 2899-2938. https://doi.org/10.1016/0020-7683(95)00255-3

Chen, W.W., Song, B., 2010. Split Hopkinson (Kolsky) Bar: Design, Testing and Applications. Springer Science \& Business Media.

De Blasio, F.V., Crosta, G.B., 2014. Simple physical model for the fragmentation of rock avalanches. Acta Mech 225, 243-252. https://doi.org/10.1007/s00707-013-0942-y

Doan, M.-L., Billi, A., 2011. High strain rate damage of Carrara marble. Geophysical Research Letters 38. https://doi.org/10.1029/2011GL049169 
Doan, M.-L., d'Hour, V., 2012. Effect of initial damage on rock pulverization along faults. Journal of Structural Geology, Fault zone structure, mechanics and evolution in nature and experiment 45, 113-124. https://doi.org/10.1016/j.jsg.2012.05.006

Doan, M.-L., Gary, G., 2009. Rock pulverization at high strain rate near the San Andreas fault. Nature Geoscience 2, 709-712. https://doi.org/10.1038/ngeo640

Dor, O., Ben-Zion, Y., Rockwell, T.K., Brune, J., 2006a. Pulverized rocks in the Mojave section of the San Andreas Fault Zone. Earth and Planetary Science Letters 245, 642-654. https://doi.org/10.1016/j.eps1.2006.03.034

Dor, O., Rockwell, T.K., Ben-Zion, Y., 2006b. Geological Observations of Damage Asymmetry in the Structure of the San Jacinto, San Andreas and Punchbowl Faults in Southern California: A Possible Indicator for Preferred Rupture Propagation Direction. Pure appl. geophys. 163, 301-349. https://doi.org/10.1007/s00024-005-0023-9

Drugan, W.J., 2001. Dynamic fragmentation of brittle materials: analytical mechanics-based models. Journal of the Mechanics and Physics of Solids 49, 1181-1208. https://doi.org/10.1016/S0022-5096(01)00002-3

Ebert, M., Hecht, L., Deutsch, A., Kenkmann, T., Wirth, R., Berndt, J., 2014. Geochemical processes between steel projectiles and silica-rich targets in hypervelocity impact experiments. Geochimica et Cosmochimica Acta 133, 257-279. https://doi.org/10.1016/j.gca.2014.02.034

Faulkner, D.R., Lewis, A.C., Rutter, E.H., 2003. On the internal structure and mechanics of large strike-slip fault zones: field observations of the Carboneras fault in southeastern Spain. Tectonophysics 367, 235-251. https://doi.org/10.1016/S0040-1951(03)00134-3

Fineberg, J., Gross, S.P., Marder, M., Swinney, H.L., 1991. Instability in dynamic fracture. Phys. Rev. Lett. 67, 457-460. https://doi.org/10.1103/PhysRevLett.67.457

Fondriest, M., Aretusini, S., Di Toro, G., Smith, S.A.F., 2015. Fracturing and rock pulverization along an exhumed seismogenic fault zone in dolostones: The Foiana Fault Zone (Southern Alps, Italy). Tectonophysics 654, 56-74. https://doi.org/10.1016/j.tecto.2015.04.015

Fondriest, M., Doan, M.-L., Aben, F., Fusseis, F., Mitchell, T.M., Voorn, M., Secco, M., Di Toro, G., 2017. Static versus dynamic fracturing in shallow carbonate fault zones. Earth and Planetary Science Letters 461, 8-19. https://doi.org/10.1016/j.epsl.2016.12.024

Fredrich, J.T., Evans, B., Wong, T.-F., 1989. Micromechanics of the brittle to plastic transition in Carrara marble. Journal of Geophysical Research: Solid Earth 94, 4129-4145. https://doi.org/10.1029/JB094iB04p04129

Frew, D.J., Forrestal, M.J., Chen, W., 2001. A split Hopkinson pressure bar technique to determine compressive stress-strain data for rock materials. Experimental Mechanics 41, 40-46. https://doi.org/10.1007/BF02323102

Ghaffari, H.O., Griffith, W.A., Barber, T.J., 2019. Energy delocalization during dynamic rock fragmentation. Geophys J Int 217, 1034-1046. https://doi.org/10.1093/gji/ggz064

Glenn, L.A., Chudnovsky, A., 1986. Strain-energy effects on dynamic fragmentation. Journal of Applied Physics 59, 1379-1380. https://doi.org/10.1063/1.336532

Grady, D., 2009. Dynamic Fragmentation of Solids, in: Shock Wave Science and Technology Reference Library, Vol. 3: Solids II. Springer, Berlin, Heidelberg, pp. 169-276. https://doi.org/10.1007/978-3-540-77080-0_4

Grady, D.E., 2010. Length scales and size distributions in dynamic fragmentation. Int J Fract 163, 85-99. https://doi.org/10.1007/s10704-009-9418-4 
Grady, D.E., 1982. Local inertial effects in dynamic fragmentation. Journal of Applied Physics 53, 322-325. https://doi.org/10.1063/1.329934

Grady, D.E., Kipp, M.E., 1985. Geometric statistics and dynamic fragmentation. Journal of Applied Physics 58, 1210-1222. https://doi.org/10.1063/1.336139

Green, S.J., Leasia, J.D., Perkins, R.D., Jones, A.H., 1972. Triaxial stress behavior of Solenhofen limestone and westerly granite at high strain rates. Journal of Geophysical Research (1896-1977) 77, 3711-3724. https://doi.org/10.1029/JB077i020p03711

Hawkes, I., Mellor, M., 1970. Uniaxial testing in rock mechanics laboratories. Engineering Geology 4, 179-285. https://doi.org/10.1016/0013-7952(70)90034-7

Hawkins, A.B., 1998. Aspects of rock strength. Bull Eng Geol Env 57, $17-30$. https://doi.org/10.1007/s100640050017

Heilbronner, R., Barrett, S., 2014. Image Analysis in Earth Sciences: Microstructures and Textures of Earth Materials. Springer-Verlag, Berlin Heidelberg. https://doi.org/10.1007/978-3-642-10343-8

Hild, F., Forquin, P., Silva, A.R.C. da, 2003. Single and multiple fragmentation of brittle geomaterials. Revue Française de Génie Civil 7, 973-1002. https://doi.org/10.1080/12795119.2003.9692529

Hogan, J.D., Castillo, J.A., Rawle, A., Spray, J.G., Rogers, R.J., 2013. Automated microscopy and particle size analysis of dynamic fragmentation in natural ceramics. Engineering Fracture Mechanics 98, 80-91. https://doi.org/10.1016/j.engfracmech.2012.11.021

Hogan, J.D., Farbaniec, L., Daphalapurkar, N., Ramesh, K.T., 2016. On Compressive Brittle Fragmentation. Journal of the American Ceramic Society 99, 2159-2169. https://doi.org/10.1111/jace.14171

Hogan, J.D., Rogers, R.J., Spray, J.G., Boonsue, S., 2012. Dynamic fragmentation of granite for impact energies of 6-28J. Engineering Fracture Mechanics 79, 103-125. https://doi.org/10.1016/j.engfracmech.2011.10.006

Housen, K.R., Holsapple, K.A., 1999. Scale Effects in Strength-Dominated Collisions of Rocky Asteroids. Icarus 142, 21-33. https://doi.org/10.1006/icar.1999.6206

Howe, S.P., Goldsmith, W., Sackman, J.L., 1974. Macroscopic static and dynamic mechanical properties of Yule marble. Experimental Mechanics 14, 337-346. https://doi.org/10.1007/BF02323559

Jaeger, J.C., Cook, N.G.W., Zimmerman, R., 2007. Fundamentals of Rock Mechanics. Blackwell Publishing.

Kenkmann, T., Poelchau, M.H., Wulf, G., 2014. Structural geology of impact craters. Journal of Structural Geology 62, 156-182. https://doi.org/10.1016/j.jsg.2014.01.015

Key, W.R.O., Schultz, R.A., 2011. Fault formation in porous sedimentary rocks at high strain rates: First results from the Upheaval Dome impact structure, Utah, USA. GSA Bulletin 123, 1161-1170. https://doi.org/10.1130/B30087.1

Kimberley, J., Ramesh, K.T., Daphalapurkar, N.P., 2013. A scaling law for the dynamic strength of brittle solids. Acta Materialia 61, 3509-3521. https://doi.org/10.1016/j.actamat.2013.02.045

Lankford, J., Blanchard, C.R., 1991. Fragmentation of brittle materials at high rates of loading. J Mater Sci 26, 3067-3072. https://doi.org/10.1007/BF01124844

Levy, S., Molinari, J.F., 2010. Dynamic fragmentation of ceramics, signature of defects and scaling of fragment sizes. Journal of the Mechanics and Physics of Solids 58, 12-26. https://doi.org/10.1016/j.jmps.2009.09.002 
Li, X.F., Li, H.B., Zhang, Q.B., Jiang, J.L., Zhao, J., 2018. Dynamic fragmentation of rock material: Characteristic size, fragment distribution and pulverization law. Engineering Fracture Mechanics 199, 739-759. https://doi.org/10.1016/j.engfracmech.2018.06.024

Liu, J.-Z., Xu, J.-Y., Lv, X.-C., Zhao, D.-H., Leng, B.-L., 2012. Experimental Study on Dynamic Mechanical Properties of Amphibolites, Sericite-quartz Schist and Sandstone under Impact Loadings. International Journal of Nonlinear Sciences and Numerical Simulation 13, 209-217. https://doi.org/10.1515/ijnsns.2011.121

Liu, K., Zhang, Q.B., Wu, G., Li, J.C., Zhao, J., 2019. Dynamic Mechanical and Fracture Behaviour of Sandstone Under Multiaxial Loads Using a Triaxial Hopkinson Bar. Rock Mech Rock Eng 52, 2175-2195. https://doi.org/10.1007/s00603-018-1691-y

Liu, K., Zhao, J., 2021. Progressive Damage Behaviours of Triaxially Confined Rocks under Multiple Dynamic Loads. Rock Mech Rock Eng 54, 3327-3358. https://doi.org/10.1007/s00603-021-02408-z

Meredith, P.G., Atkinson, B.K., Hillmann, N.B., 1984. Progress in Experimental Petrology, in: 6th Report. NERC Pubs. Ser. D. No. 25, Swindon, UK.

Millon, O., Ruiz-Ripoll, M.L., Hoerth, T., 2016. Analysis of the Behavior of Sedimentary Rocks Under Impact Loading. Rock Mech Rock Eng 49, 4257-4272. https://doi.org/10.1007/s00603-016-1010-4

Mitchell, T.M., Ben-Zion, Y., Shimamoto, T., 2011. Pulverized fault rocks and damage asymmetry along the Arima-Takatsuki Tectonic Line, Japan. Earth and Planetary Science Letters 308, 284-297. https://doi.org/10.1016/j.epsl.2011.04.023

Paliwal, B., Ramesh, K.T., 2008. An interacting micro-crack damage model for failure of brittle materials under compression. Journal of the Mechanics and Physics of Solids 56, 896923. https://doi.org/10.1016/j.jmps.2007.06.012

Peppard, D.W., Webb, H.N., Dennis, K., Vierra, E., Girty, G.H., Rockwell, T.K., Blanton, C.M., Brown, J.F., Goldstein, A.I., Kastama, K.W., Korte-Nahabedian, M.A., Puckett, D., Richter, A.K., 2018. Micro-scale damage characterized within part of a dismembered positive flower structure, San Jacinto fault, southern California, USA. Journal of Structural Geology 112, 53-68. https://doi.org/10.1016/j.jsg.2018.04.014

Pieri, M., Burlini, L., Kunze, K., Stretton, I., Olgaard, D.L., 2001. Rheological and microstructural evolution of Carrara marble with high shear strain: results from high temperature torsion experiments. Journal of Structural Geology 23, 1393-1413. https://doi.org/10.1016/S0191-8141(01)00006-2

Poelchau, M.H., Kenkmann, T., Hoerth, T., Schäfer, F., Rudolf, M., Thoma, K., 2014. Impact cratering experiments into quartzite, sandstone and tuff: The effects of projectile size and target properties on spallation. Icarus 242, 211-224. https://doi.org/10.1016/j.icarus.2014.08.018

Rae, A.S.P., Kenkmann, T., Padmanabha, V., Poelchau, M.H., Schäfer, F., 2020. Dynamic Compressive Strength and Fragmentation in Felsic Crystalline Rocks. Journal of Geophysical Research: Planets 125, e2020JE006561. https://doi.org/10.1029/2020JE006561

Ramesh, K.T., Hogan, J.D., Kimberley, J., Stickle, A., 2015. A review of mechanisms and models for dynamic failure, strength, and fragmentation. Planetary and Space Science, VIII Workshop on Catastrophic Disruption in the Solar System 107, 10-23. https://doi.org/10.1016/j.pss.2014.11.010 
Ravi-Chandar, K., Knauss, W.G., 1984a. An experimental investigation into dynamic fracture: I. Crack initiation and arrest. Int J Fract 25, 247-262. https://doi.org/10.1007/BF00963460

Ravi-Chandar, K., Knauss, W.G., 1984b. An experimental investigation into dynamic fracture: II. Microstructural aspects. Int J Fract 26, 65-80. https://doi.org/10.1007/BF01152313

Reches, Z., Dewers, T.A., 2005. Gouge formation by dynamic pulverization during earthquake rupture. Earth and Planetary Science Letters 235, 361-374.

https://doi.org/10.1016/j.epsl.2005.04.009

Rempe, M., Mitchell, T., Renner, J., Nippress, S., Ben-Zion, Y., Rockwell, T., 2013. Damage and seismic velocity structure of pulverized rocks near the San Andreas Fault. Journal of Geophysical Research: Solid Earth 118, 2813-2831. https://doi.org/10.1002/jgrb.50184

Rockwell, T., Sisk, M., Girty, G., Dor, O., Wechsler, N., Ben-Zion, Y., 2009. Chemical and Physical Characteristics of Pulverized Tejon Lookout Granite Adjacent to the San Andreas and Garlock Faults: Implications for Earthquake Physics. Pure appl. geophys. 166, 1725-1746. https://doi.org/10.1007/s00024-009-0514-1

Rosakis, A.J., 1999. Explosion at the Parthenon: Can We Pick Up the Pieces? (Technical Report No. 99-3). GALCIT SM.

Rowe, C.D., Griffith, W.A., 2015. Do faults preserve a record of seismic slip: A second opinion. Journal of Structural Geology 78, 1-26. https://doi.org/10.1016/j.jsg.2015.06.006

Sagy, A., Korngreen, D., 2012. Dynamic branched fractures in pulverized rocks from a deep borehole. Geology 40, 799-802. https://doi.org/10.1130/G33194.1

Schindelin, J., Arganda-Carreras, I., Frise, E., Kaynig, V., Longair, M., Pietzsch, T., Preibisch, S., Rueden, C., Saalfeld, S., Schmid, B., Tinevez, J.-Y., White, D.J., Hartenstein, V., Eliceiri, K., Tomancak, P., Cardona, A., 2012. Fiji: an open-source platform for biological-image analysis. Nature Methods 9, 676-682. https://doi.org/10.1038/nmeth.2019

Schröckenfuchs, T., Bauer, H., Grasemann, B., Decker, K., 2015. Rock pulverization and localization of a strike-slip fault zone in dolomite rocks (Salzach-Ennstal-MariazellPuchberg fault, Austria). Journal of Structural Geology 78, 67-85. https://doi.org/10.1016/j.jsg.2015.06.009

Sharon, E., Fineberg, J., 1999. Confirming the continuum theory of dynamic brittle fracture for fast cracks. Nature 397, 333-335. https://doi.org/10.1038/16891

Van Stappen, J.F., De Kock, T., De Schutter, G., Cnudde, V., 2019. Uniaxial compressive strength measurements of limestone plugs and cores: a size comparison and X-ray CT study. Bull Eng Geol Environ 78, 5301-5310. https://doi.org/10.1007/s10064-018-014480

Wang, H., Ramesh, K.T., 2004. Dynamic strength and fragmentation of hot-pressed silicon carbide under uniaxial compression. Acta Materialia 52, 355-367. https://doi.org/10.1016/j.actamat.2003.09.036

Wilson, B., Dewers, T., Reches, Z., Brune, J., 2005. Particle size and energetics of gouge from earthquake rupture zones. Nature 434, 749-752. https://doi.org/10.1038/nature03433

Xia, K., Yao, W., 2015. Dynamic rock tests using split Hopkinson (Kolsky) bar system - A review. Journal of Rock Mechanics and Geotechnical Engineering 7, 27-59. https://doi.org/10.1016/j.jrmge.2014.07.008

Yao, W., Xu, Y., Xia, K., 2020. Damage Evolution During Rock Pulverization Induced by Dynamic Compressive Loading. Journal of Geophysical Research: Solid Earth 125, e2020JB019388. https://doi.org/10.1029/2020JB019388 
Yuan, F., Prakash, V., Tullis, T., 2011. Origin of pulverized rocks during earthquake fault rupture. Journal of Geophysical Research: Solid Earth 116. https://doi.org/10.1029/2010JB007721

Zhang, Q.B., Zhao, J., 2014. A Review of Dynamic Experimental Techniques and Mechanical Behaviour of Rock Materials. Rock Mech Rock Eng 47, 1411-1478. https://doi.org/10.1007/s00603-013-0463-y

Zhang, Z.X., Kou, S.Q., Yu, J., Yu, Y., Jiang, L.G., Lindqvist, P.-A., 1999. Effects of loading rate on rock fracture. International Journal of Rock Mechanics and Mining Sciences 36, 597-611. https://doi.org/10.1016/S0148-9062(99)00031-5

Zhou, F., Molinari, J.-F., Ramesh, K.T., 2006a. Analysis of the brittle fragmentation of an expanding ring. Computational Materials Science, Proceedings of the 14th International Workshop on Computational Mechanics of Materials 37, 74-85. https://doi.org/10.1016/j.commatsci.2005.12.017

Zhou, F., Molinari, J.-F., Ramesh, K.T., 2006b. Effects of material properties on the fragmentation of brittle materials. Int J Fract 139, 169-196. https://doi.org/10.1007/s10704-006-7135-9

Zhou, Y.X., Xia, K., Li, X.B., Li, H.B., Ma, G.W., Zhao, J., Zhou, Z.L., Dai, F., 2011. Suggested Methods for Determining the Dynamic Strength Parameters and Mode-I Fracture Toughness of Rock Materials, in: Ulusay, R. (Ed.), The ISRM Suggested Methods for Rock Characterization, Testing and Monitoring: 2007-2014. Springer International Publishing, Cham, pp. 35-44. https://doi.org/10.1007/978-3-319-07713-0_3

Zou, C., Wong, L.N.Y., 2016. Size and Geometry Effects on the Mechanical Properties of Carrara Marble Under Dynamic Loadings. Rock Mech Rock Eng 49, 1695-1708. https://doi.org/10.1007/s00603-015-0899-3

Zwiessler, R., Kenkmann, T., Poelchau, M.H., Nau, S., Hess, S., 2017. On the use of a split Hopkinson pressure bar in structural geology: High strain rate deformation of Seeberger sandstone and Carrara marble under uniaxial compression. Journal of Structural Geology 97, 225-236. https://doi.org/10.1016/j.jsg.2017.03.007 


\title{
Supplementary Material of "Dynamic Compressive Strength and Fragmentation in Sedimentary and Metamorphic Rocks"
}

\author{
Auriol S. P. Rae ${ }^{1,2}$, Thomas Kenkmann', Vivek Padmanabha ${ }^{1,3}$, Michael H. Poelchau', \\ Frank Schäfer ${ }^{1,3}$, Matthias A. Dörffler ${ }^{3}$, Louis Müller ${ }^{1}$ \\ ${ }^{1}$ Institute of Earth and Environmental Sciences - Geology, Albert-Ludwigs Universität Freiburg, \\ Albertstrasse 23b, 79104 Freiburg, Germany. \\ ${ }^{2}$ Department of Earth Sciences, University of Cambridge, Cambridge CB2 3EQ, UK \\ ${ }^{3}$ Fraunhofer Institute for High-Speed Dynamics, Ernst-Mach-Institut (EMI), Ernst-Zermelo- \\ strasse 4, 79104 Freiburg, Germany.
}

Corresponding author: Auriol S. P. Rae (auriol.rae@geologie.uni-freiburg.de) 


\section{Introduction}

A GitHub repository that corresponds to this manuscript has been made publicly available (https://github.com/ASprae/Dynamic-Strength-and-Fragmentation). The repository contains all the data acquired, used, and plotted in this study:

- Petrophysical properties of all lithologies in this study and that of Rae et al. (2020).

- Summaries of all mechanical experiments, quasi-static and dynamic, including all the results from Rae et al. (2020) used in this study.

- Raw data for the SHPB experiments and a script for processing the data.

- All sieve data in this study and Rae et al. (2020).

- All images used to derive fragment shape distributions, including the starting image and the final thresholded image, data outputs from analysis of those images from Fiji, and python scripts for the analysis of that data.

- Python scripts that implement the geometric fragmentation algorithms described in the text and analyse the fragment shape distributions of those geometric fragmentation patterns.

The methodology used in this study is very similar to a previous study by the same authors (Rae et al., 2020). The following text (Supplementary Text 1) is adapted from the Supplementary Material of that paper. Several sections, where we could not improve the clarity of the writing, have been directly copied from Rae et al., (2020).

\section{Supplementary Text 1: Split Hopkinson Pressure Bar Methodology}

Split-Hopkinson Pressure Bars (SHPBs) consist of three units: a striker with acceleration apparatus, an incident bar, and a transmission bar (Figure S1). The sample is placed between the incident and transmission bars. In this study, titanium alloy $\left(E_{B}=110 \mathrm{GPa}, \rho_{B}=4.43 \mathrm{~g} \mathrm{~cm}^{-3}\right)$ bars were used for each bar and the striker. The bars and striker were $5 \mathrm{~cm}$ in diameter. All experiments used a $25 \mathrm{~cm}$-long cylindrical striker. The pulse generated by the direct impact of 
this striker on the incident bar would be inappropriate for the testing of brittle materials. Brittle materials must be loaded at a steady rate to ensure uniform stress throughout the sample, i.e. a so-called "stress equilibrium" or "dynamic force balance" (Xia and Yao, 2015; Zhang and Zhao, 2014; Zhou et al., 2011). This "triangular" pulse shape was achieved by the use of a pulse shaper placed at the front end of the incident bar. We used the same type of pulse shaper used by Rae et al. (2020); pre-hit cuboids of aluminium foam. The aluminium foam had an original thickness of $2 \mathrm{~cm}$, and was cut such that the foam covered the entire $5 \mathrm{~cm}$ diameter incident bar. The aluminium foam has an original bulk density of $\sim 300 \mathrm{~kg} \mathrm{~m}^{-3}$ and porosity of $\sim 90 \%$. The behaviour of the pulse-shaper can be modified to be appropriate for the testing of the sample material by pre-hitting the pulse-shaper prior to the experiment. All pulse shapers were pre-hit by the striker at a velocity of $\sim 10 \mathrm{~m} \mathrm{~s}^{-1}$, resulting in a final thickness of $\sim 7.5 \mathrm{~mm}$, consistent with the pulse shapers used by Rae et al. (2020). To avoid damage to the bars during the experiment, 2 mm thick titanium alloy plates were attached to the bar ends with silicon grease, and a thin sheet of Teflon is placed between the sample and the titanium plates. The sample was then placed between the incident and transmission bars, within a secure box lined with a polyethylene bag so that the sample could be recovered. We used a cradle of adhesive tape within the box to keep the sample in place prior to the experiment.

Strain gauges on the incident and transmission bars measure the pulse before and after it has contacted the sample. Each bar has two strain gauges placed diametrically across the bar at the same distance from the sample; the two signals on each bar are averaged to account for any bending of the bar. The signals contain three important components from which the stress and strain history of the sample is determined. The incident pulse, $\varepsilon_{i}$, the transmitted pulse, $\varepsilon_{t}$, and the reflected pulse (measured in the incident bar), $\varepsilon_{r}$. Experiments were always conducted such that the incident and reflected pulses were distinct and did not overlap. Signal processing occurred by the following steps: first, the signals are time-adjusted to account for the distance between the sample and the strain gauges; second, high-frequency noise is filtered; and third, frequency dependent dispersion (Pochhammer-Chree dispersion) is corrected for (See Gama et al., 2004). 
Once $\varepsilon_{i}, \varepsilon_{t}$, and $\varepsilon_{r}$ were corrected, stress, strain-rate, and strain as a function of time were obtained by:

$$
\begin{gathered}
\sigma_{a}(t)=\frac{A_{B}}{A_{S}} E_{B}\left(\varepsilon_{i}(t)+\varepsilon_{r}(t)\right),(1) \\
\sigma_{b}(t)=\frac{A_{B}}{A_{S}} E_{B} \varepsilon_{t}(t),(2) \\
\dot{\varepsilon}(t)=\frac{C_{B}}{L_{S}}\left(\varepsilon_{i}(t)-\varepsilon_{r}(t)-\varepsilon_{t}(t)\right),(3) \\
\varepsilon(t)=\frac{C_{B}}{L_{S}} \int_{0}^{t}\left(\varepsilon_{i}(t)-\varepsilon_{r}(t)-\varepsilon_{t}(t)\right) d t,(4)
\end{gathered}
$$

where $\sigma_{\boldsymbol{a}}(\boldsymbol{t})$ and $\boldsymbol{\sigma}_{\boldsymbol{b}}(\boldsymbol{t})$ are the stresses at the front and back of the sample respectively, which, in well-carried out experiment should be equal at all times (i.e. stress equilibrium); $\dot{\boldsymbol{\varepsilon}}(\boldsymbol{t})$ and $\boldsymbol{\varepsilon}(\boldsymbol{t})$ are the longitudinal strain rate and longitudinal strain respectively; $\boldsymbol{A}_{\boldsymbol{B}}, \boldsymbol{E}_{\boldsymbol{B}}$, and $\boldsymbol{C}_{\boldsymbol{B}}$ are the area of the bar, elastic modulus of the bar, and sound speed of the bar respectively, while $\boldsymbol{A}_{\boldsymbol{S}}$ and $\boldsymbol{L}_{\boldsymbol{S}}$ are the area of the sample and length of the sample respectively. Use of equations 1-4 is commonly known as the "3-wave analysis" method of determining stress and strain histories from SHPB experiments (Gray, 2000).

In an SHPB experiment, the sample undergoes a history of strain rate as defined by Equation 3. However, for the purposes of comparing experiments at different rates a "representative" strain rate for the experiment must be chosen (Aben et al., 2017). In this study we have used the same definition of the representative strain rate as used by Rae et al. (2020), representative strain rate is defined as the average strain rate between the times where stress is at $25 \%$ of the peak stress, and when peak stress occurs. Determining the representative strain rate as an average of the strain rate history is fundamentally similar to the approaches of Yuan et al. (2011) and Zwiessler et al. (2017). Other methods of defining the representative strain rate include: picking the maximum strain rate prior to yielding (Barber and Griffith, 2017; Doan and Gary, 2009), picking the strain rate at the time of peak stress (Zhang et al., 2009), or the "plateau" value of the strain rate history (Xia et al., 2008). Our method of determining the representative strain rate as an average value was chosen for several reasons: first, while strain rate plateaus were easy to identify at small loading rates, at larger rates it becomes increasingly 
challenging to unambiguously identify the plateau. The chosen method typically picks the plateau in the low rate experiments and avoids subjective choices in the high-rate experiments. Secondly, picking one value of the strain rate is not representative of the whole experiment; peak rate can be strongly affected by oscillations in the stress wave while the rate at peak stress in low rate experiments, where substantial elastic strain may be recovered by the sample, are typically close to zero. An advantage of our method of picking the representative strain rate is that the variability of strain rate can be represented by the standard deviation of the determined average rate. The choice to start taking the average value from $25 \%$ of the peak stress is arbitrary, however this point avoids non-linear, concave-upwards regions of the stress-strain curves at low stresses that result from compaction of silicon grease, Teflon, and air bubbles at the sample bar interfaces (Rae et al., 2020).

Strain rate can be varied between experiments by increasing the striker velocity, this was generally possible up to the maximum safety limit of the equipment used, while maintaining stress equilibrium and an appropriate strain rate history during loading. However, if samples are particularly strong, i.e. requiring large striker velocities to cause failure, this may leave a limited amount of strain rate space available to safely operate in. Consequently, subject to maintaining stress equilibrium, avoiding inertial stress generation, and generating an appropriate strain rate history during loading, it can be possible to vary the size of the samples to explore a greater range of conditions. Ideal samples for SHPB experiments have a length-to-diameter ratio between 1:2 and 1:1 and have a cross sectional area close to that of the bars (Gray, 2000; Zhang and Zhao, 2014; Zhou et al., 2011). Consequently, most samples used in our experiments were $\sim 41 \mathrm{~mm}$ in diameter and length. However, in a number of cases, changing the size and aspect ratio of the sample was required. First, strain rate can be increased by using a shorter sample, or conversely, strain rate can be decreased by using a longer sample. Secondly, the minimum striker velocity required to cause failure can be decreased by decreasing the cross-sectional area of the sample. In turn this allows a greater range of striker velocities to be used, and therefore a greater range of strain rates. We note that changes in sample size and aspect ratio are expected to have an effect on the material strength (Hawkes and Mellor, 1970; Hawkins, 1998), and potentially 
the fragment size. However, we found no statistically significant systematic change of strength or fragmentation over the sizes used in our experiments.

Measurements of dynamic material strength can be significantly affected by the inability of the sample to deform fast enough for the applied stress; this inertia can contribute to the stress (Forrestal et al., 2007; Kolsky, 1949). Inertia can produce additional longitudinal stress, $\boldsymbol{\sigma}_{\boldsymbol{l}}(\boldsymbol{t})$, and confining radial and hoop stresses, $\boldsymbol{\sigma}_{\boldsymbol{r}}(\boldsymbol{t})$ and $\boldsymbol{\sigma}_{\boldsymbol{\theta}}(\boldsymbol{t})$ respectively:

$$
\begin{gathered}
\sigma_{l}(t)=\frac{v^{2} \rho a^{2}}{2} \ddot{\varepsilon},(5) \\
\sigma_{r}(t)=\frac{v(3-2 v) \rho a^{2}}{12(1-v)} \ddot{\varepsilon},(6) \\
\sigma_{\theta}(t)=\frac{v(5-6 v) \rho a^{2}}{12(1-v)} \ddot{\varepsilon},(7)
\end{gathered}
$$

where $\rho, v$, and $a$ are the density, Poisson's ratio, and radius of the specimen. $\ddot{\boldsymbol{\varepsilon}}$ is the second derivative of the longitudinal strain with respect to time. A properly conducted SHPB experiment minimizes these effects, primarily due to the use of pulse-shapers. In the experiments conducted in this study, the average maximum longitudinal inertial stress of the experiments in this study was $95.5 \mathrm{kPa}$, with a maximum value for an experiment being $323.9 \mathrm{kPa}$ (see GitHub Repository), over two orders of magnitude less than the peak stress of the corresponding experiment. Consequently, longitudinal inertial stresses introduce an error of $<0.34 \%$ of the failure stress, significantly less than the inter-sample variability of the strength of each sample. The average maximum radial and hoop inertial stresses of the experiments in this study were $191.1 \mathrm{kPa}$ and $256.0 \mathrm{kPa}$, with maximum values of $619.8 \mathrm{kPa}$ and $871.7 \mathrm{kPa}$, respectively (see GitHub Repository). Assuming a Mohr-Coulomb failure envelope up to these confining pressures and a typical coefficient of friction for rocks between 0.5 and 1.0 (Jaeger et al., 2007), the inertial confining stresses make only a negligible contribution to the failure strength. 


\section{Supplementary Text 2: Fragment Image Acquisition and Processing}

To determine the shape properties of fragments, we initially chose to manually pick the fragments from each sample, starting from the largest fragments, and lay them upon a piece of black card such that all fragments were fully separated from each other (Supplementary Figure 3). We were able to hand pick all fragments from the selected samples down to fragment sizes (sieve diameters) of $2 \mathrm{~mm}$. Beyond this size, it was impractical to hand pick and separate each fragment. These hand-picked fragments were then imaged with a Canon EOS 1200D camera at a pixel resolution of $\sim 140$ pixels $/ \mathrm{cm}$.

Fragments smaller than $2 \mathrm{~mm}$ were imaged with a slightly different method. In this case, our method was modified due to a number of considerations: first, that fragments would need to range in size from a maximum size of $2 \mathrm{~mm}$ (and the images would require a statistically valid number of fragments of this size) down a smallest size as dictated by the requirement that the smallest fragments must be resolved by at least 200 pixels (Kröner et al., 2013), second, that the vast number of fragments and their required dispersal prohibits imaging of the entire sample, and finally, that the fragments could not be manually separated prior to image acquisition. Following these considerations, we used a modified Petrographic Image Capture and Archiving Tool (PICAT; Crawford and Bennight, 2010) with a Canon EOS 5D Mark II Camera, originally designed for the acquisition of whole thin-section images. To acquire images with a sufficient number of $\sim 2 \mathrm{~mm}$ fragments, a resolution of $\sim 700$ pixels $/ \mathrm{cm}$ was used. Thus, the minimum particle size that could be imaged with at least 200 pixels was $\sim 0.2 \mathrm{~mm}$. However, due to the practicalities of distinguishing fragment dust and image noise from the fragments themselves and ensuring that the images could be adequately thresholded and segmented, we restricted the minimum fragment size to $0.5 \mathrm{~mm}$. Thus, all fragments between 0.5 and $2 \mathrm{~mm}$ of a sample were recombined (after sieving) and mixed. The mixed subsamples were then divided into quarters, and each quarter was scattered over a piece of black card and imaged (Supplementary Figure 4).

Images were processed using the Fiji software package (Schindelin et al., 2012). All images were converted to 8-bit color, thresholded using the Li thresholding algorithm, and a median filter applied. At this point, the image processing method for the fragments smaller than $2 \mathrm{~mm}$ differed from the fragments larger than $2 \mathrm{~mm}$. Due to the lack of separation between all fragments less than $2 \mathrm{~mm}$, a distance-transform watershed (MorphoLibJ; Legland et al., 2016) was applied to segment 
any merged fragments. Borgefors distance weighting was used and the "Dynamic" parameter, which determines the intensity of the search for regional minima of the inverse of the distance transform, was chosen between 2 and 5 such that images were neither systematically oversegmented, nor under-segmented. Following this processing, the areas, perimeters, and best-fitting ellipses of each segmented fragment were determined.

The first stage of post-processing was a further filtering step, where remaining noise and anomalously small fragments (smaller than the expected minimum size of $2 \mathrm{~mm}$ or $0.5 \mathrm{~mm}$ ) and rock dust were removed. These particles could readily be distinguished from the fragments of interest from fragment size distributions, which were distinctly bimodal; with a local minimum in the probability distribution function at particle sizes of $\sim 0.5 \mathrm{~mm}$. All particles finer than that local minimum were eliminated from further analysis. Following this filtering, the shapes of the fragments were determined. Upon checking that the distributions of fragment shapes for the fragments from 0.5 to $2 \mathrm{~mm}$ were consistent (similar average, range, and distribution shape) between each of the 4 images for each sample, we combined the data from all images to generate single fragment shape distributions for each sample. 


\section{Supplementary Figures}

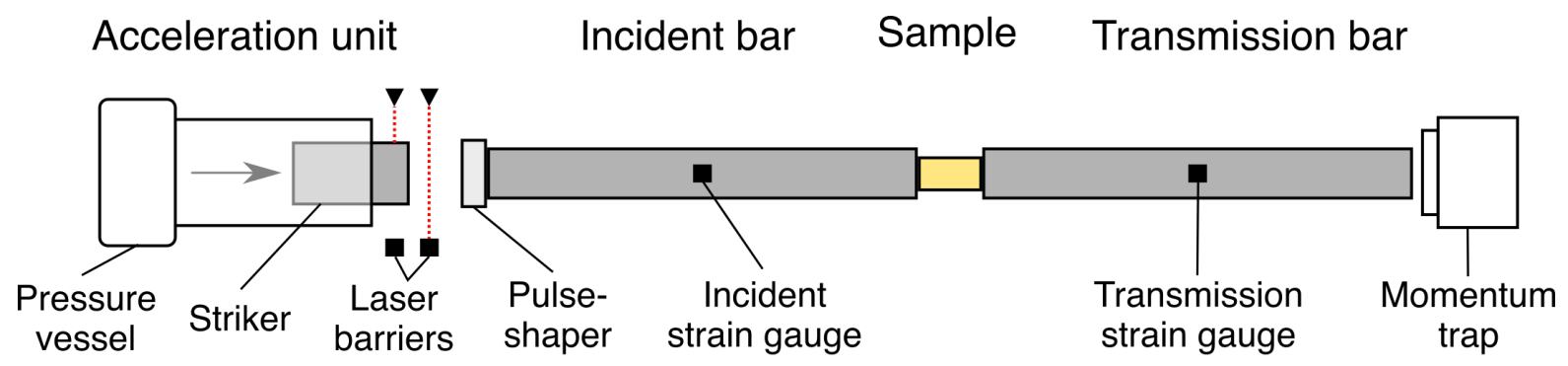

Figure S1. Schematic split Hopkinson pressure bar set-up.

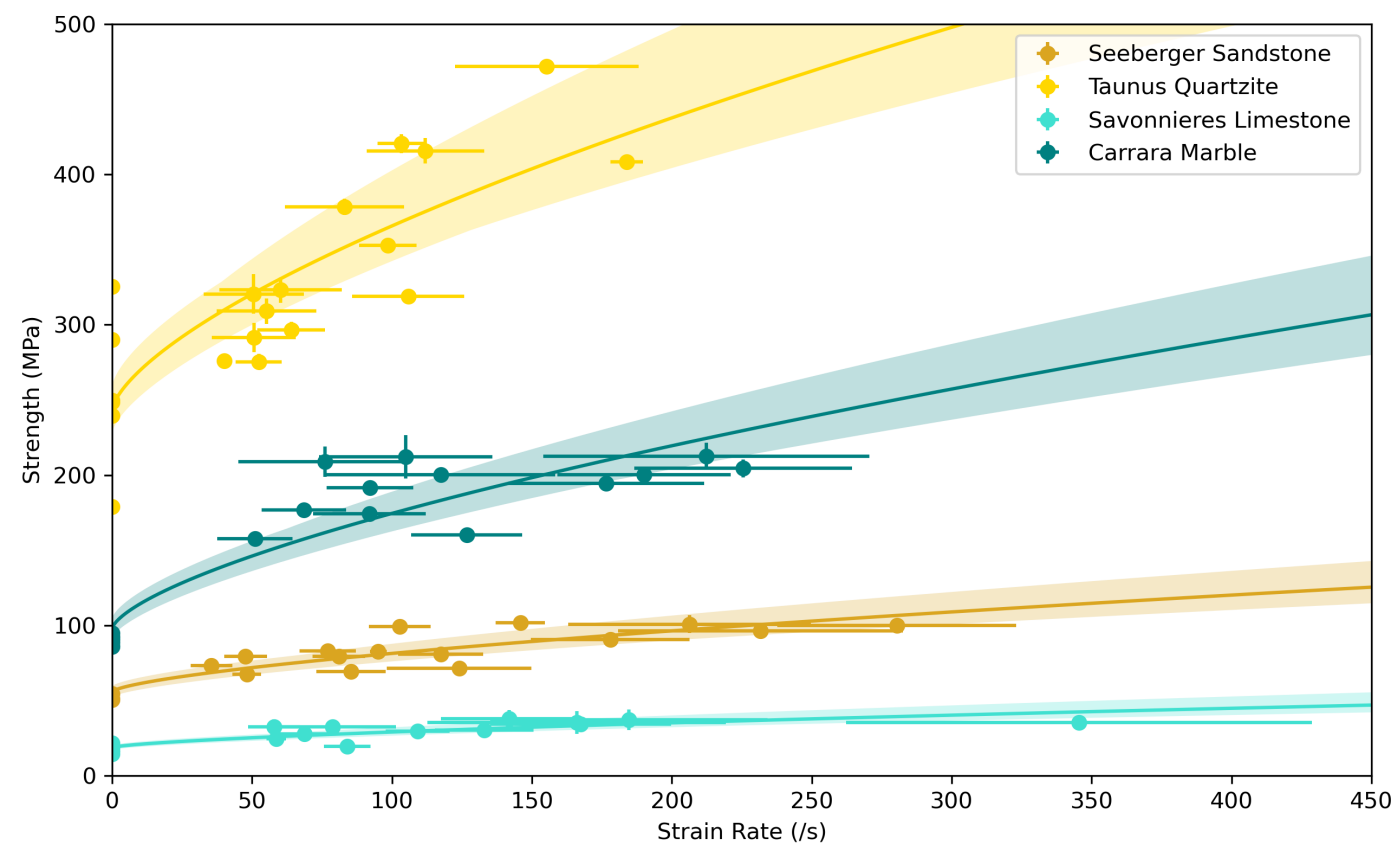

Figure S2. Compressive Strengths from quasi-static and dynamic testing at various strain rates. Each suite follows the universal scaling relationship of Kimberley et al. (2013), each fitted curve is shown with $1 \sigma$ error envelopes. Figure is equivalent to Figure 2, but with a linear x-axis. 

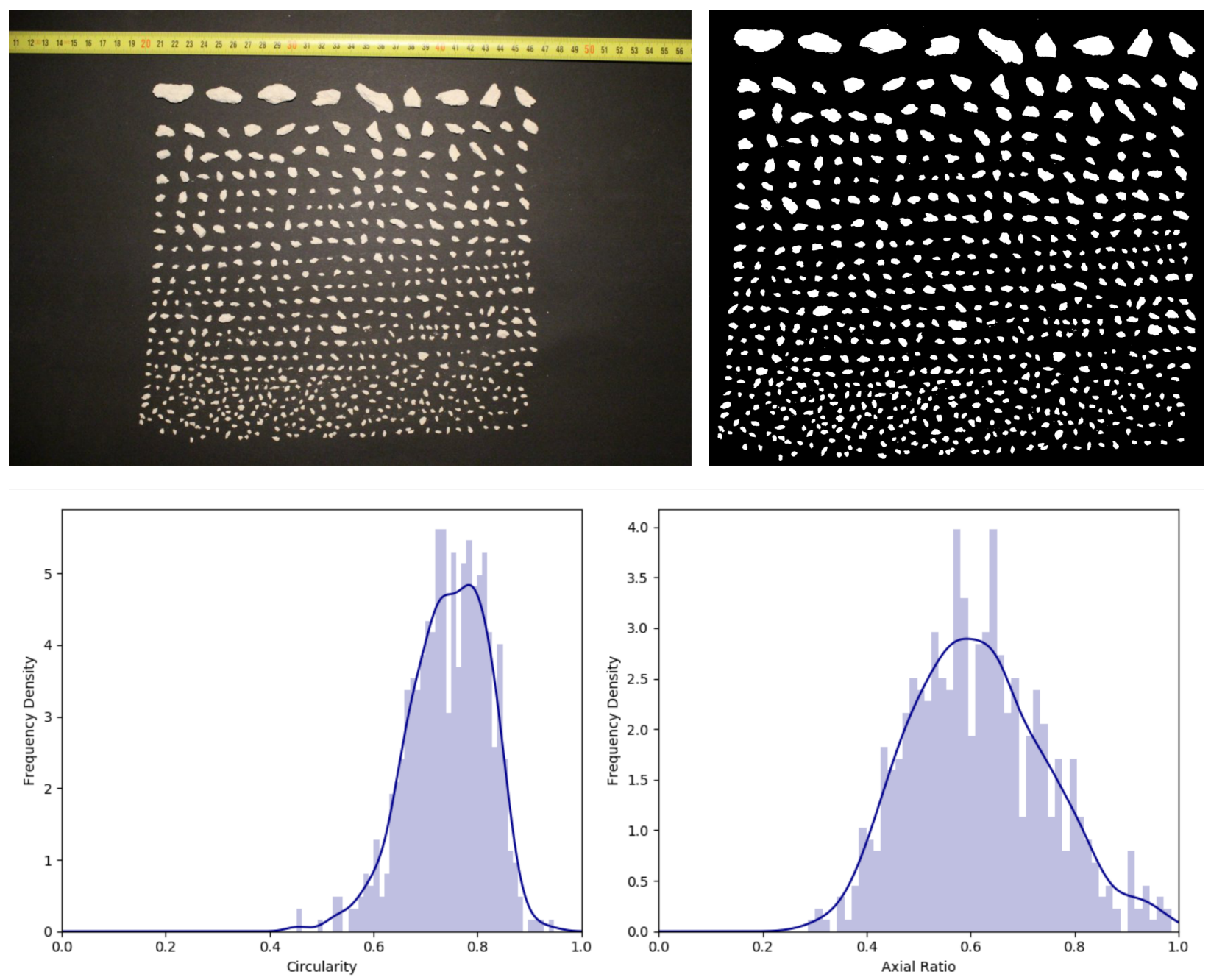

Figure S3. Example of fragment shape analysis. Here, fragments $>2 \mathrm{~mm}$ for a sample of Savonnières Limestone are shown (SaLi_008). Above) original and thresholded images of the sample. Below) Post-processed frequency distributions of circularity and axial ratio. 

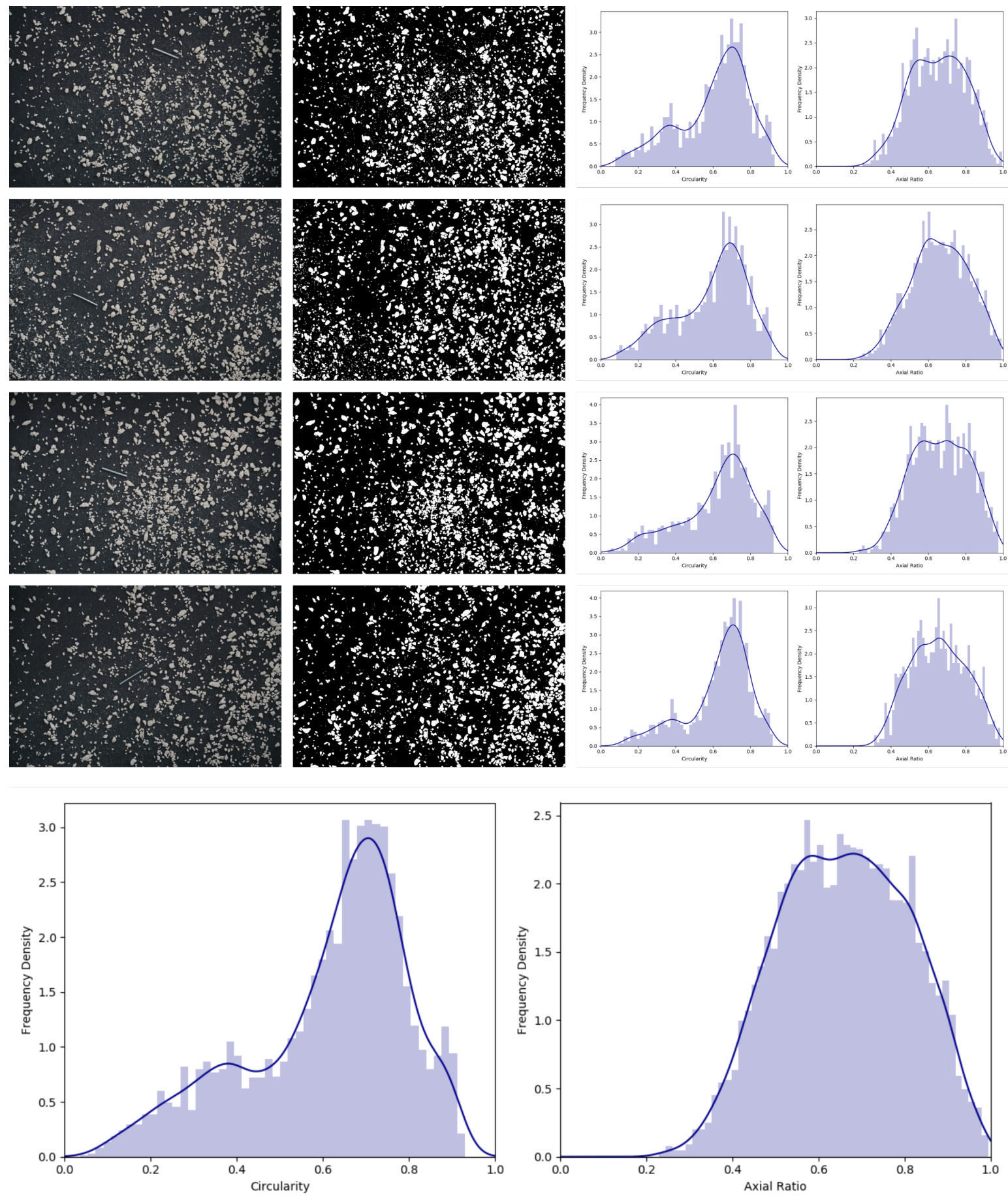

Figure S4. Example of fragment shape analysis. Here, fragments between 0.5 and $2 \mathrm{~mm}$ for a sample of Savonnières Limestone are shown (SaLi_008). Above) 4 rows, each corresponding to different quarters of the same sample showing the original and thresholded images, and the circularity and axial ratio distributions of each image. Below) The final fragment shape distribution for the sample, made by compiling all the data for each of the four quarters above. 


\section{References}

Aben, F.M., Doan, M.-L., Gratier, J.-P., Renard, F., 2017. Coseismic Damage Generation and Pulverization in Fault Zones, in: Fault Zone Dynamic Processes. American Geophysical Union (AGU), pp. 47-80. https://doi.org/10.1002/9781119156895.ch4

Barber, T., Griffith, W.A., 2017. Experimental constraints on dynamic fragmentation as a dissipative process during seismic slip. Philosophical Transactions of the Royal Society A: Mathematical, Physical and Engineering Sciences 375, 20160002. https://doi.org/10.1098/rsta.2016.0002

Doan, M.-L., Gary, G., 2009. Rock pulverization at high strain rate near the San Andreas fault. Nature Geoscience 2, 709-712. https://doi.org/10.1038/ngeo640

Forrestal, M.J., Wright, T.W., Chen, W., 2007. The effect of radial inertia on brittle samples during the split Hopkinson pressure bar test. International Journal of Impact Engineering 34, 405-411. https://doi.org/10.1016/j.ijimpeng.2005.12.001

Gama, B.A., Lopatnikov, S.L., Gillespie, J.W., 2004. Hopkinson bar experimental technique: A critical review. Appl. Mech. Rev 57, 223-250. https://doi.org/10.1115/1.1704626

Gray, G.T., 2000. Classic Split-Hopkinson Pressure Bar Testing, in: Kuhn, H., Medlin, D. (Eds.), Mechanical Testing and Evaluation. ASM International, pp. 462-476. https://doi.org/10.31399/asm.hb.v08.a0003296

Hawkes, I., Mellor, M., 1970. Uniaxial testing in rock mechanics laboratories. Engineering Geology 4, 179-285. https://doi.org/10.1016/0013-7952(70)90034-7

Hawkins, A.B., 1998. Aspects of rock strength. Bull Eng Geol Env 57, 17-30. https://doi.org/10.1007/s100640050017

Jaeger, J.C., Cook, N.G.W., Zimmerman, R., 2007. Fundamentals of Rock Mechanics. Blackwell Publishing.

Kimberley, J., Ramesh, K.T., Daphalapurkar, N.P., 2013. A scaling law for the dynamic strength of brittle solids. Acta Materialia 61, 3509-3521. https://doi.org/10.1016/j.actamat.2013.02.045

Kolsky, H., 1949. An Investigation of the Mechanical Properties of Materials at very High Rates of Loading. Proc. Phys. Soc. B 62, 676-700. https://doi.org/10.1088/0370$1301 / 62 / 11 / 302$

Legland, D., Arganda-Carreras, I., Andrey, P., 2016. MorphoLibJ: integrated library and plugins for mathematical morphology with ImageJ. Bioinformatics 32, 3532-3534. https://doi.org/10.1093/bioinformatics/btw413

Rae, A.S.P., Kenkmann, T., Padmanabha, V., Poelchau, M.H., Schäfer, F., 2020. Dynamic Compressive Strength and Fragmentation in Felsic Crystalline Rocks. Journal of Geophysical Research: Planets 125, e2020JE006561. https://doi.org/10.1029/2020JE006561

Schindelin, J., Arganda-Carreras, I., Frise, E., Kaynig, V., Longair, M., Pietzsch, T., Preibisch, S., Rueden, C., Saalfeld, S., Schmid, B., Tinevez, J.-Y., White, D.J., Hartenstein, V., Eliceiri, K., Tomancak, P., Cardona, A., 2012. Fiji: an open-source platform for biological-image analysis. Nature Methods 9, 676-682. https://doi.org/10.1038/nmeth.2019

Xia, K., Nasseri, M.H.B., Mohanty, B., Lu, F., Chen, R., Luo, S.N., 2008. Effects of microstructures on dynamic compression of Barre granite. International Journal of Rock Mechanics and Mining Sciences 45, 879-887. https://doi.org/10.1016/j.ijrmms.2007.09.013 
Xia, K., Yao, W., 2015. Dynamic rock tests using split Hopkinson (Kolsky) bar system - A review. Journal of Rock Mechanics and Geotechnical Engineering 7, $27-59$. https://doi.org/10.1016/j.jrmge.2014.07.008

Yuan, F., Prakash, V., Tullis, T., 2011. Origin of pulverized rocks during earthquake fault rupture. Journal of Geophysical Research: Solid Earth 116. https://doi.org/10.1029/2010JB007721

Zhang, M., Wu, H.J., Li, Q.M., Huang, F.L., 2009. Further investigation on the dynamic compressive strength enhancement of concrete-like materials based on split Hopkinson pressure bar tests. Part I: Experiments. International Journal of Impact Engineering, Seventh International Conference on Shock and Impact Loads on Structures 36, 1327 1334. https://doi.org/10.1016/j.ijimpeng.2009.04.009

Zhang, Q.B., Zhao, J., 2014. A Review of Dynamic Experimental Techniques and Mechanical Behaviour of Rock Materials. Rock Mech Rock Eng 47, 1411-1478. https://doi.org/10.1007/s00603-013-0463-y

Zhou, Y.X., Xia, K., Li, X.B., Li, H.B., Ma, G.W., Zhao, J., Zhou, Z.L., Dai, F., 2011. Suggested Methods for Determining the Dynamic Strength Parameters and Mode-I Fracture Toughness of Rock Materials, in: Ulusay, R. (Ed.), The ISRM Suggested Methods for Rock Characterization, Testing and Monitoring: 2007-2014. Springer International Publishing, Cham, pp. 35-44. https://doi.org/10.1007/978-3-319-07713-0_3

Zwiessler, R., Kenkmann, T., Poelchau, M.H., Nau, S., Hess, S., 2017. On the use of a split Hopkinson pressure bar in structural geology: High strain rate deformation of Seeberger sandstone and Carrara marble under uniaxial compression. Journal of Structural Geology 97, 225-236. https://doi.org/10.1016/j.jsg.2017.03.007 